Hydrol. Earth Syst. Sci., 17, 1851-1869, 2013

www.hydrol-earth-syst-sci.net/17/1851/2013/

doi:10.5194/hess-17-1851-2013

(C) Author(s) 2013. CC Attribution 3.0 License.

\title{
Thermal management of an unconsolidated shallow urban groundwater body
}

\author{
J. Epting ${ }^{1}$, F. Händel ${ }^{2,3}$, and P. Huggenberger ${ }^{1}$ \\ ${ }^{1}$ Department of Environmental Sciences, Applied and Environmental Geology, University of Basel, Bernoullistr. 32, \\ 4056 Basel, Switzerland \\ ${ }^{2}$ Department Monitoring and Exploration Technologies, UFZ - Helmholtz Centre for Environmental Research, \\ Permoserstr. 15, 04318 Leipzig, Germany \\ ${ }^{3}$ Institute for Groundwater Management, Technische Universität Dresden, Bergstr. 66, 01069 Dresden, Germany
}

Correspondence to: J. Epting (jannis.epting@unibas.ch)

Received: 24 April 2012 - Published in Hydrol. Earth Syst. Sci. Discuss.: 6 June 2012

Revised: 5 March 2013 - Accepted: 11 April 2013 - Published: 15 May 2013

\begin{abstract}
This study presents the development of tools for the sustainable thermal management of a shallow unconsolidated urban groundwater body in the city of Basel (Switzerland). The concept of the investigations is based on (1) a characterization of the present thermal state of the urban groundwater body, and (2) the evaluation of potential mitigation measures for the future thermal management of specific regions within the groundwater body.

The investigations focus on thermal processes downgradient of thermal groundwater use, effects of heated buildings in the subsurface as well as the thermal influence of river-groundwater interaction. Investigation methods include (1) short- and long-term data analysis, (2) high-resolution multilevel groundwater temperature monitoring, as well as (3) 3-D numerical groundwater flow and heat transport modeling and scenario development. The combination of these methods allows for the quantifying of the thermal influences on the investigated urban groundwater body, including the influences of thermal groundwater use and heated subsurface constructions. Subsequently, first implications for management strategies are discussed, including minimizing further groundwater temperature increase, targeting "potential natural" groundwater temperatures for specific aquifer regions and exploiting the thermal potential.
\end{abstract}

\section{Introduction}

Thermal groundwater regimes in urban areas are affected by numerous anthropogenic changes, such as surface sealing or subsurface constructions as well as groundwater use. Additionally, the extension of subsurface infrastructures and the diffuse heat input of heated buildings have resulted in elevated groundwater temperatures observed in many urban areas (e.g. Taniguchi et al., 1999, 2005, 2007; Ferguson and Woodbury, 2004, 2007; Zhu et al., 2010). Also, in northwestern Switzerland, Basel, groundwater temperatures have increased significantly, and have reached up to $17^{\circ} \mathrm{C}$ in an area where the long-term average annual air temperature is approximately $10^{\circ} \mathrm{C}$ (Epting et al., 2011). This increase is substantial, considering the groundwater temperatures in areas not influenced by anthropogenic activities should be comparable to the average annual air temperature.

Prediction of groundwater temperatures is an important issue for groundwater protection in urban areas (Florides and Kalogirou, 2007; Pouloupatis et al., 2011; Shi et al., 2008), in particular when considering the missing rules for resource management in urban areas as well as current deficiencies in adaption strategies related to future environmental development and mitigation measures for infrastructures. Therefore, understanding groundwater heat transport is essential for the design, performance analysis and impact assessment of thermal devices (e.g. Fujii et al., 2005).

The design and construction of shallow geothermal systems has been investigated comprehensively. Spitler (2005) 
reviewed past ground-source heat pump system research, from the 1940s to present and Lund et al. (2005) provide a comprehensive review of geothermal systems worldwide. Fry (2009) focused in his work on the regulation of the increasing number of open-loop ground source heat pumps being installed into the confined chalk aquifer of central London. The main issues are: (1) how can production temperatures (cooling or heating) be maintained throughout the years? (2) How far extents the area influenced by cooling or heating around the injector (Banks, 2009)?

Evaluating the effect of geothermal systems on subsurface environments requires appropriate monitoring and modeling tools. Recent availability of simple and reliable temperature measurement devices and the advancement of 3-D heat transport models facilitate investigations of subsurface heat transport at different scales. Fujii et al. (2007) proposed the development of suitability maps for the Chikushi Plain (western Japan) based on local geological and hydrogeological information for ground-coupled heat pump systems using fieldsurvey data and numerical groundwater and heat transport models. Zhu et al. (2010) evaluated the case-specific potential heat content in urban aquifers and quantified available capacities for space heating. Nam and Ooka (2010) performed numerical simulation of ground heat and water transfer for groundwater heat pump system based on real-scale experiment. Händel et al. (2013) numerically assessed on a regional scale a future geothermal use of an unconsolidated shallow aquifer utilizing large open-loop groundwater heat pumps. Detailed groundwater temperature measurements in Cologne (Germany) and Winnipeg (Canada) reveal high subsurface temperature distributions in the centers of both cities and indicate a warming trend of up to $5 \mathrm{~K}$. Such geothermal potentials are also observed in other cities such as Shanghai and Tokyo and can supply heating demand even for decades. Also Allen et al. (2003) propose that Northern European countries can utilize the urban heat island effect to generate low enthalpy geothermal energy for space heating and cooling systems (dual heating and cooling functions) in buildings, provided a suitable aquifer underlies the urban area.

Dahlem and Heinrich (1999) and Dahlem (2000) investigated the influence of groundwater flow on the heat loss of heated cellars. They found that heat loss due to advective groundwater flow can be in the order of 10 times higher compared to solely conductive heat loss. Ampofo et al. (2006) reviewed groundwater cooling systems in London. They show that environmental influence of building parts that reach into the groundwater has increased the pressure on architects, engineers and building operators to reduce the use of air conditioning in favor of more passive cooling solutions. However, the proposed solutions are limited to new-build projects.

Currently, in most urban areas, regulations for water resource management and geothermal energy use are sparse and limited to the rule "first come, first served". Also in urban areas, groundwater-based heating and (especially) cooling schemes are being planned, sometimes with minimal hydrogeological input (Banks, 2009). Haehnlein et al. (2010) compiled the international status of the use of shallow geothermal energy. Bonte et al. (2011) investigated the environmental risks and policy developments in the Netherlands and European Union related to underground thermal energy storage. Commonly, groundwater temperature changes are restricted by installation guidelines or occasionally by governmental environmental agencies. For instance, in Switzerland, the maximum allowed temperature difference induced from geothermal energy use is $3 \mathrm{~K}$ down-gradient of thermal groundwater use in relation to a "natural state" of groundwater temperatures without anthropogenic influence (GSchV, 2001).

This study analyses the thermal regime of the shallow unconsolidated urban groundwater body of Basel. The analyses show how to predict the influence of thermal systems and urban subsurface development on the basis of field-scale hydrogeological data as well as 3-D numerical groundwater flow and heat transport modeling and scenario development. A concept for adaptive resource management and shallow thermal groundwater use in the investigated urban area is presented, which is based on the characterization of the present thermal state of the urban Ground Water Body (GWB) (CEC, 2000).

Several factors affecting the magnitude and timing of temperature increases and decreases are examined, with focus on (1) thermal groundwater use for cooling purposes; (2) the effect of heated buildings reaching into the unsaturated and saturated aquifer, with emphasis on building density and the urban heat island effect; and (3) the role of river-groundwater interaction. A set of scenarios is presented that focuses on the compensation of past influences on the thermal groundwater regime such as thermal groundwater use and urbanization.

\section{Settings}

Many Swiss valleys which are underlain by unconsolidated alluvial sediments belong to the most densely populated areas. Furthermore, these aquifers are important for drinking and process water supplies and, as they maintain a relatively stable geothermal source or sink, the aquifers are suited for the geothermal use of groundwater.

The investigated shallow unconfined aquifer in the Basel area consists of late Pleistocene gravels deposited by the river Rhine. The thickness of the gravel deposits range between 10 and $34 \mathrm{~m}$. The depth from the surface to the groundwater table (average hydrological boundary conditions) ranges from 6 to $30 \mathrm{~m}$ (mean $19 \mathrm{~m}$; Fig. 1). The gravel deposits are underlain by an aquitard consisting of mud to clay rich sediments, Oligocene in age.

Figure 2 shows the land use within the study area. In total, $38 \%$ of the area is sealed by infrastructure and $23 \%$ by buildings, $6 \%$ is covered by water and $33 \%$ by open space. The southeast and the northern part of the area are densely 


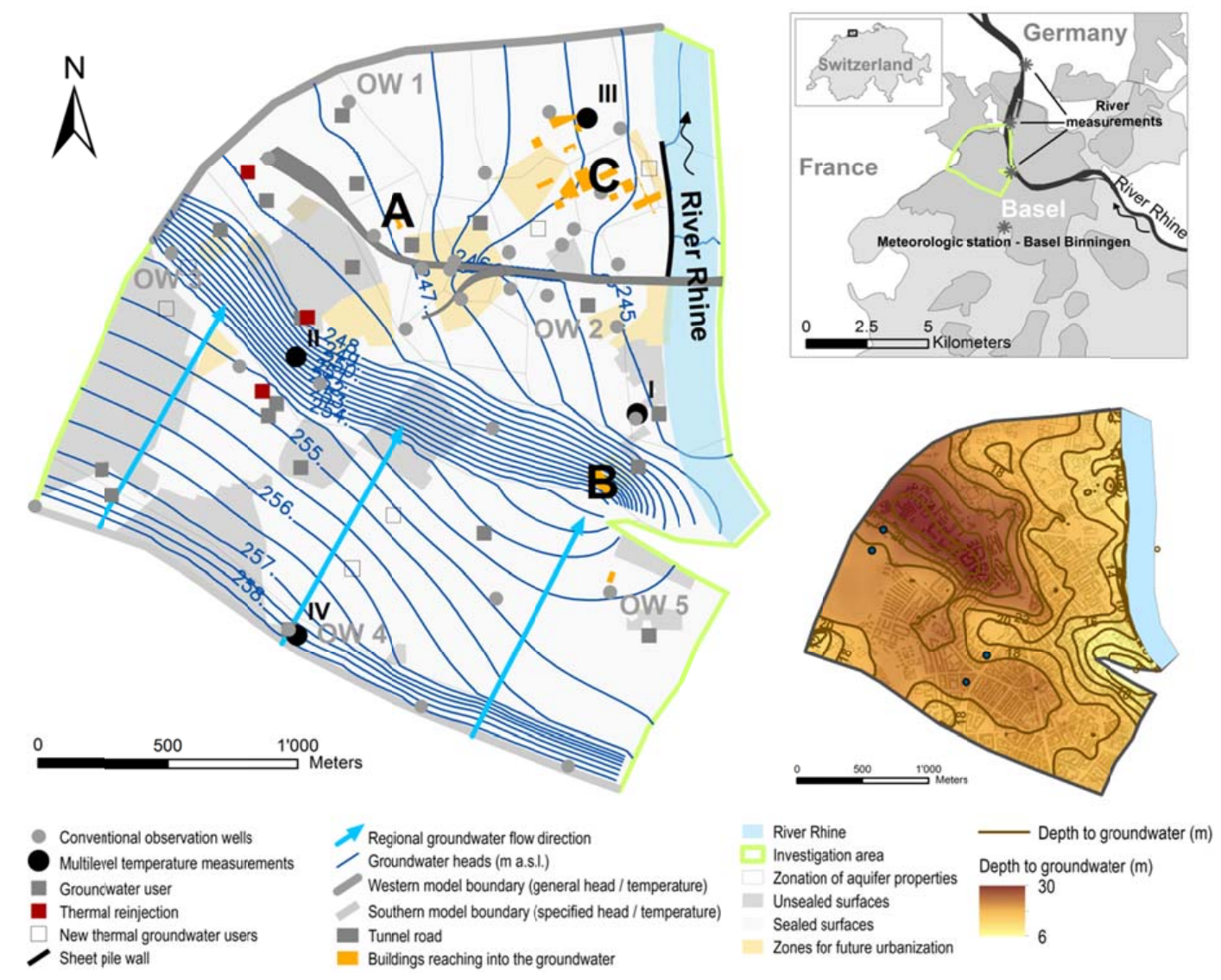

Fig. 1. Left panel: study area including model boundary conditions for flow and heat transport. OW1-5: data from conventional observation wells. I-IV: locations of multilevel temperature measurements. A: Waste incineration facility; B: Biozentrum; and C; Northern industrial area. Also shown is the regional groundwater flow regime with the main flow directions. Note the steep hydraulic gradient in the center of the modeling domain resulting from the progression of the bedrock as well as the backwater effects along the tunnel road and sheet pile wall. Upper right panel: location of the study area in Switzerland and in the agglomeration of Basel. Lower right panel: depth from the surface to an average groundwater table ranging between 6 and $30 \mathrm{~m}$.

urbanized. Parts of the investigated area were formerly contaminated by industrial activities (Epting et al., 2008a). A total of 13 industrial wells are operated, the average amount of groundwater extracted from the aquifer is about $30 \mathrm{~L} \mathrm{~s}^{-1}$, and approximately $3.5 \mathrm{~L} \mathrm{~s}^{-1}$ is injected back to the aquifer (Fig. 1). Cooling using groundwater has gained popularity in recent years (e.g. Clarkson et al., 2009). Among the reasons for this are the excellent energy efficiency and the increasing viability of water extraction systems. For groundwater cooling systems, cold water is abstracted from one part of the aquifer system (the "cold" well; typically at $6-12{ }^{\circ} \mathrm{C}$, depending on the aquifer and location) and is used via a heat exchanger for cooling the building. The resultant heated water is then recharged into the aquifer at a different location (the "hot" well). As in the city of Basel a heating network exists, groundwater currently only is used for cooling purposes.

Basel, like other European cities (Lopez et al., 2010), is a fairly old city when compared, e.g. to many cities in northern America. Therefore, Basel will have experienced downward heat flow to greater depth than observed in other studies (cf. Ferguson and Woodbury, 2004, 2006). Although many newer buildings have insulated basements, this is a relatively new practice and a significant amount of heat loss will have already occurred within the investigated area. Furthermore, the subsurface levels of large buildings located within the investigated area are used as workplaces (e.g. laboratories) and are heated above standard values for current subsurface buildings in Switzerland, which are in the order of $20^{\circ} \mathrm{C}$.

In addition to building parts that reach into the aquifer, further constructions lie within the aquifer; this includes a $3.2 \mathrm{~km}$ long subsurface highway that partly lies within the aquifer perpendicular to the main groundwater flow direction as well as a $550 \mathrm{~m}$ long sheet pile wall at the river board (Figs. 1 and 2).

The groundwater regime of the area has already been investigated intensively within the scope of various stresses on the GWB during the construction of a tunnel highway in the northwestern area of Basel, Switzerland (Huggenberger et 


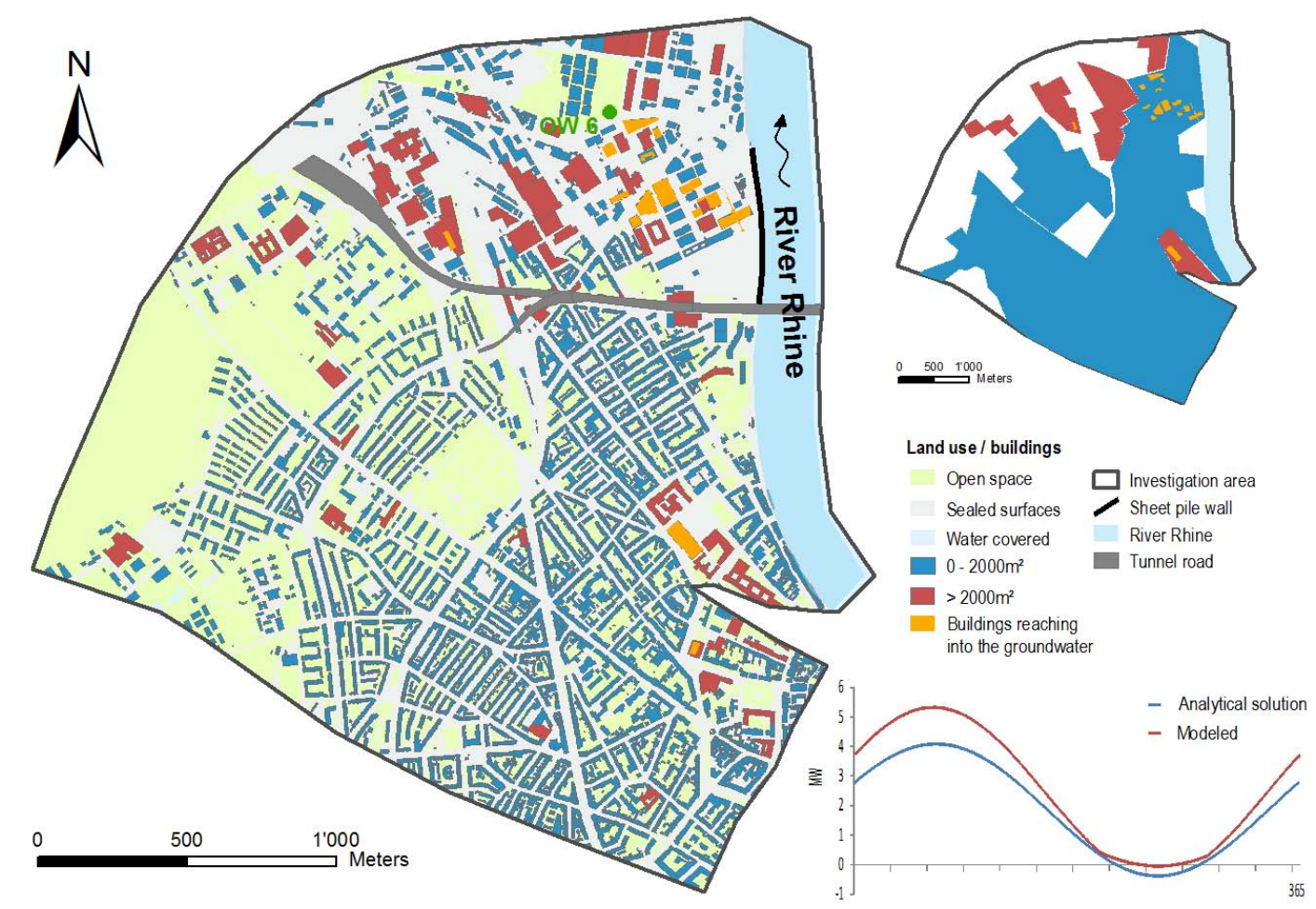

Fig. 2. Left panel: land use in the study area OW6: Temperature data used for heat flux calculation of large buildings reaching into the groundwater. Upper right panel: areas delineated for the consideration of heated buildings in the subsurface (small buildings with basement areas between 0 and $2000 \mathrm{~m}^{2}$ were considered within model layer 1 ; larger buildings with basement areas greater than $2000 \mathrm{~m}^{2}$ were considered in model layers 1 and 2; for buildings reaching into the groundwater the exact depth could be considered). Lower right panel: heat flux of small and larger buildings derived by an analytical solution and calibrated with the heat transport model.

al., 2004; Epting et al., 2008a,b). The main direction of the regional groundwater flow is from south to north and from west to east (Fig. 1). A steep gradient of the hydraulic heads in the middle of the model area coincides with a steep slope of the bedrock surface in this area, resulting in flow velocities above $5 \mathrm{~m} \mathrm{~d}^{-1}$ (Fig. 1). By contrast, comparatively low hydraulic gradients and groundwater flow velocities below $0.5 \mathrm{~m} \mathrm{~d}^{-1}$ can be observed in the northern industrial area behind the sheet pile wall on the river board (see below; Fig. 1).

\section{Methods}

\subsection{Monitoring}

For the interpretation of groundwater temperature, two types of data sets were available: (1) temperature data that are measured additionally to groundwater head within 27 conventional observation wells run by the Agency for Environment Basel-Stadt (AUE BS), and (2) high-resolution data from four multilevel observation wells.

The purpose for installing the conventional observation wells was to measure the groundwater head and to take groundwater samples. Due to temperature sensors becoming affordable in the last couple of years, the existing observation wells were supplemented with temperature devices. However, as these wells are constructed and instrumented nonuniformly (vertical position of the temperature sensor within the observation well; position of the observation wells' screen within the flow field, etc.), the comparability of different temperature time series is restricted.

The multilevel observation wells have been constructed and instrumented for temperature measurements only and therefore provide more consistent temperature data. However, to date no long-term data sets are available. The four multilevel observation wells (Fig. 1) provide continuous temperature measurements at discrete points vertically within the aquifer at 0.5 to $1 \mathrm{~m}$ depth intervals. Thermistor thermometers (PT 100, Ott Logosens data logger) were used, which can read temperature at $0.01 \mathrm{~K}$ accuracy. For two of the multilevel observation wells (II and III), filter gravels were placed at the depth of the screening sections, which consecutively were separated by bentonite. For the other two multilevel observation wells (I and IV) the entire annulus space was filled with bentonite. Both construction designs are expected to prevent short circuiting and thermal free convection vertically. The multilevel observation wells focus on capturing several processes: (I) river-groundwater interaction effects on thermal groundwater regimes; (II) down-gradient 
influence of thermal groundwater use on the thermal groundwater regime; and (III) down-gradient thermal effects of building parts reaching into the aquifer, including seasonal heating phases. Additionally, a fourth (IV) device for multilevel temperature monitoring was installed for calibrating the southern model boundary.

The head and temperature of the river Rhine is measured at three locations by the Federal Office for the Environment, Switzerland (FOEN) and the AUE BS (Fig. 1). The mean annual river water temperature for the period 1995 to 2009 was $12.7^{\circ} \mathrm{C}$; the maximum and minimum river water temperatures for this period were 26.2 and $3.1^{\circ} \mathrm{C}$, respectively.

\subsection{Model setup and calibration}

The movement of thermal plumes through the subsurface is controlled by groundwater velocity and thermal properties of the aquifer. Physical processes affecting heat transport within an aquifer include advection, dispersion and diffusion. The diffusion of heat depends on the thermal conductivity and volumetric heat capacity of the aquifer. In a composite medium, such as an aquifer, the properties of both the fluid and the solid phase of the porous media have to be considered. In general, for the exchange and heat transfer between the aquifer system with the upper boundary (e.g. from the atmosphere or through the unsaturated zone) or surface waters (e.g. rivers, lakes), a transfer coefficient is required.

For the present study the flow and heat transport models were set up in FEFLOW ${ }^{\complement}$ (Diersch, 2002) and have been calibrated for the time series of the year 2010 (27 observation wells with head and temperature data). Furthermore, the temperature measurements of the multilevel observation wells were used to further calibrate the model. The area covers $2720 \mathrm{~m} \times 2860 \mathrm{~m}$ (about $8 \mathrm{~km}^{2}$; Figs. 1 and 2). The aquifer base includes the information of more than 400 drill cores and was modeled using $\mathrm{GoCAD}^{\complement}$ (Geological Objects Computer Aided Design).

The model mesh consists of 81756 elements and 44308 nodes. A total of 18 layers and 19 slices were integrated to adequately include the measurement levels of the multilevel temperature sensors. The lowermost layer accounts for heat storage processes in the underlying consolidated bedrock and was uniformly set to $20 \mathrm{~m}$ thickness. A thickness of $0.5 \mathrm{~m}$ for the overlying layers was distributed uniformly from the basement; the uppermost layer reaches up to the surface and includes the unsaturated zone. The topography was derived from a DEM with $25 \mathrm{~m}$ resolution and high-precision echo sounding of the riverbed. The resulting volume of the 3-D groundwater model amounts to $1.45 \times 10^{9} \mathrm{~m}^{3}$ (without bedrock layer).

The distribution of horizontal hydraulic conductivity zones is based on data sets from pumping tests and drill core descriptions which were available from the geological database developed by the Applied and Environmental Geology of the University of Basel (GeoData), as well as
Table 1. Material properties selected for the saturated and unsaturated domain of the heat transport models.

\begin{tabular}{ll}
\hline Parameter & \\
\hline$n(-)$ & 0.12 \\
Longitudinal dispersivity $\alpha L(\mathrm{~m})$ & 20 \\
Transversal dispersivity $\alpha T(\mathrm{~m})$ & 2 \\
Transfer rate from the surface through the river & $1.25 \times 10^{4}$ \\
bed and unsaturated zone to the groundwater table & \\
(In/Out) $T_{\mathrm{r}}\left(\mathrm{J} \mathrm{m}^{-2} \mathrm{~d}^{-1} \mathrm{~K}^{-1}\right)$ & \\
Volumetric heat capacity of the gravel $c_{\mathrm{S}}\left(\mathrm{J} \mathrm{m}^{-3} \mathrm{~K}^{-1}\right)$ & $2.87 \times 10^{6}$ \\
Thermal conductivity of the gravel $\lambda_{\mathrm{s}}\left(\mathrm{J} \mathrm{m}^{-1} \mathrm{~s}^{-1} \mathrm{~K}^{-1}\right)$ & 2.70 \\
Volumetric heat capacity of water $c_{\mathrm{W}}\left(\mathrm{J} \mathrm{m}^{-3} \mathrm{~K}^{-1}\right)$ & $4.20 \times 10^{6}$ \\
Thermal conductivity of water $\lambda_{\mathrm{W}}\left(\mathrm{J} \mathrm{m}^{-1} \mathrm{~s}^{-1} \mathrm{~K}^{-1}\right)$ & $6.00 \times 10^{-1}$ \\
Unsaturated flow porosity $\varepsilon$ & 0.38 \\
Residual saturation $\Theta_{\mathrm{r}}(-)$ & 0.12 \\
Maximum saturation $\Theta_{\mathrm{s}}(-)$ & 1.00 \\
Shape parameter $\alpha(1 / \mathrm{m})$ & 3.99 \\
Shape parameter $n(-)$ & 3.50 \\
\hline
\end{tabular}

considerations of fluvial depositional processes. Based on these data sets, values for the hydraulic conductivity range from $1 \times 10^{-4}$ to $5 \times 10^{-3} \mathrm{~m} \mathrm{~s}^{-1}$ (Epting et al., 2008a,b). The ratio of horizontal to vertical hydraulic conductivity as well as the ratio of longitudinal to transversal dispersivity is assumed to be 10 . An effective porosity of 0.12 and a longitudinal dispersivity of $20 \mathrm{~m}$ were derived from regional field studies, including results from dye tracer tests.

Flow in the unsaturated zone is calculated by the Richards equation (Richards, 1931), and the empirical Mualem vanGenuchten model (Vangenuchten, 1980) is used to describe the shape of the retention curve and the saturation-dependent hydraulic conductivity. For the parameterization, information on residual and maximum saturations as well as shape parameters are needed. Parameter estimation was performed using the network prediction system Rosetta Lite (Schaap et al., 2001) (Table 1). The complete model area is considered homogenously regarding these parameters and a thicknessweighted average was calculated from borehole information of the multilevel observation wells.

Values for thermal conductivity and heat capacity for the porous media and groundwater were derived from the literature (Table 1). Markle et al. (2006) characterized the twodimensional thermal conductivity distribution in a sand and gravel aquifer and provide values for thermal conductivities for glacial soils. Otto (2010) compiled thermal conductivities of shallow unconsolidated rock for northern Germany. Fluid viscosity dependencies were incorporated choosing the standard settings in FEFLOW $^{\complement}$ using an empirical relationship, as can be found in the literature (Lever and Jackson, 1985; Hassanizadeh, 1988).

In order to adequately discretize the time-varying thermal and hydraulic boundary condition of the river Rhine, daily 


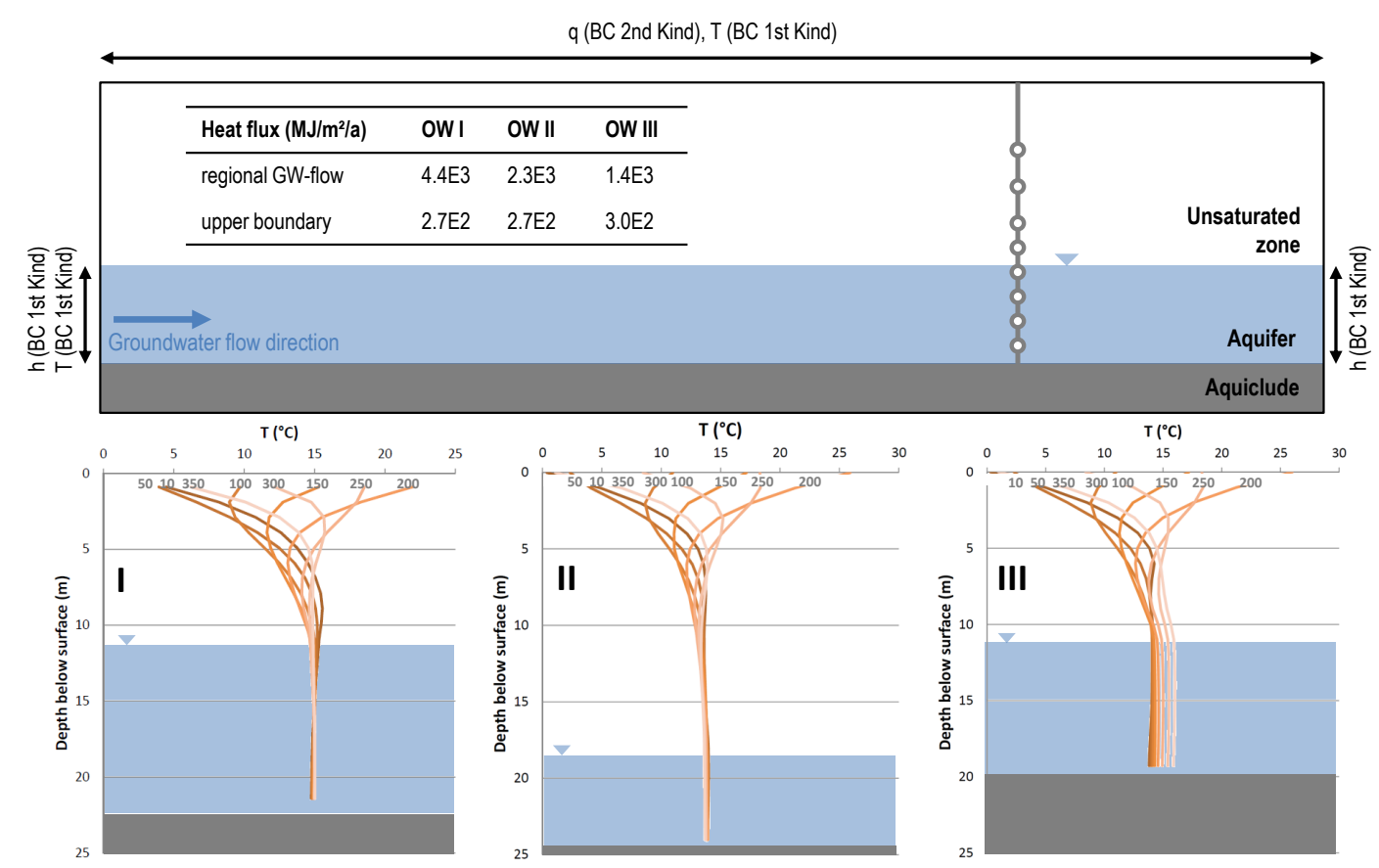

Fig. 3. Top panel: conceptual setup for local 2-D (I and II; for locations see Fig. 1) and 3-D (III; for location see Fig. 1) models, including model boundary conditions for flow and heat transport and a schematically representation of a multilevel temperature measurement device within the flow field; the imbedded table summarizes the cumulated yearly heat fluxes across selected model boundaries for three of the multilevel observation wells. Bottom panel: modeled temperature tautochrones for three of the multilevel observation wells; grey numbers represent tautochrones of selected days in the year 2010.

time intervals of temperature and head data were chosen. An initial distribution of groundwater head and temperature were interpolated on the basis of measured head and temperature data in the conventional observation wells. In the following the model boundaries for flow and thermal transport (sources and sinks) are defined.

\subsubsection{Upper boundary conditions and thermal influence of the unsaturated zone}

Areal groundwater recharge by percolating meteoric water (areal inflow on top) is derived from the Basel/Binningen

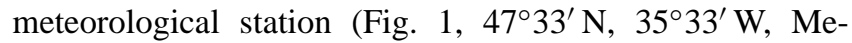
teoSwiss 1940). To account for more (e.g. urbanized) or less (e.g. public parks) sealed surfaces, the model area was subdivided into zones (Figs. 1 and 2). For the two zones monthly running averages of cumulated daily precipitation, which were reduced by a factor of $1 / 30$ or $1 / 3$, respectively, were introduced as groundwater recharge (see Huggenberger et al., 2006).

The upper thermal boundary was considered as Cauchy boundary condition ( $3 \mathrm{rd} \mathrm{kind}$ ) at the top of the unsaturated zone and is based on temperature measurements at $20 \mathrm{~cm}$ depth within the soil at the Basel/Binningen meteorological station (see Table 1 for calibrated transfer rate). Numerically, the boundary condition is assigned to areas with lower building density to represent the interaction with the atmosphere, which is in contrast to the approach used for areas with high building density (see below).

In order to adequately consider the thermal influence of the unsaturated zone for three locations, where multilevel observation wells exist, high-resolution local models were set up. For multilevel observation wells I (near river, cf. Fig. 1) and II (model center, cf. Fig. 1) 2-D vertical models were set up, and for well III a 3-D model was set up (to account for the flow and transport processes around a large building reaching to the bedrock, cf. Figs. 1 and 2). Multilevel observation well IV was excluded as it was used to calibrate the southern model boundary. For the 2-D models a fine discretization for the unsaturated and saturated zone was used and a bottom layer of $20 \mathrm{~m}$ thickness was added to account for vertical transport processes into and out of the impermeable bedrock (see above). Figure 3 summarizes the chosen flow and heat transport boundary conditions. The input data upand down-gradient of the modeling domain as well as aquifer flow and thermal parameters of the saturated zone were derived from the regional heat transport model. The upper boundary corresponds to the regional heat transport model (see above). Hydraulic properties of the unsaturated zone were estimated using the network prediction system Rosetta Lite (Schaap et al., 2001) and a homogenously distributed thickness-weighted average of the lithological properties is 

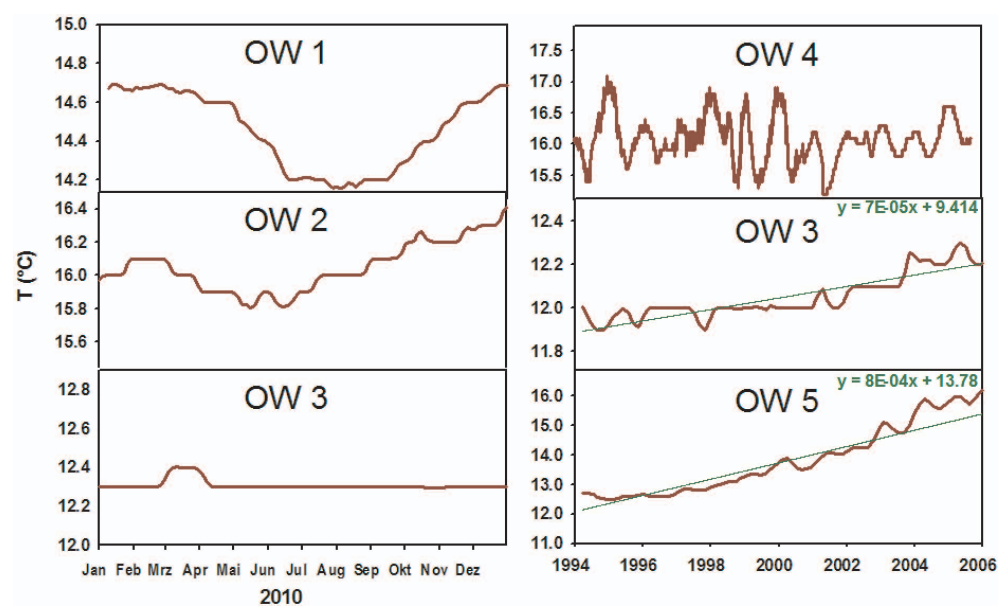

Fig. 4. Left panels: selected time series for the year 2010 illustrating the short-term and annual development of groundwater temperatures (note the different axis intercepts; see text for further explanation and for locations Fig. 1). Right panels: selected time series for the years 1994 to 2006 illustrating the long-term and seasonal development of groundwater temperatures (note the different axis intercepts; see text for further explanation and for locations Fig. 1).

derived from the borehole reports of the multilevel observation wells (see above).

\subsubsection{River model boundary}

For the investigated groundwater body, apart from flood events, exfiltration of groundwater into the river Rhine is the dominating exchange process. During average flow conditions the influence of river water temperature on groundwater temperatures (within the aquifer near to the river) is dominated by heat conduction. Temperature differences between surface and groundwater can be used to identify inor exfiltration zones and to quantify exchange rates through the streambed (Constantz, 1998; Constantz and Stonestrom, 2003). However, in cases where the dominating exchange process is groundwater exfiltration into surface waters, alterations in vertical temperature distributions within the streambed are reduced or not detectable.

Therefore, the following procedure was chosen for the river model boundary: (1) selection of a transient Cauchy boundary condition (3rd kind) considering daily intervals of head and river water temperature data (Fig. 1); (2) calibration of flow and heat transfer rates (see above, Table 1) for regions beneath the river which correspond to river bed conductance; and (3) zonation of regions with different conductance corresponding to the location of the sheet pile wall at the river board as well as to the thickness of the gravel layer in the river bed, which is thickest in the south (Fig. 1).

\subsubsection{Lower boundary}

The lower boundary was defined by the basal heat flux of approx. $0.07 \mathrm{~W} \mathrm{~m}^{-2}$ at the lowermost model slice. It was derived from results obtained during several deep drilling projects in the region of Basel (Häring, 2002).

\subsubsection{Northwestern model boundary}

The northwestern model boundary was defined as (a) no flow along a flow line extending from the southern model boundary to the step in the bedrock located in the middle of the model domain (cf. Fig. 1), and (b) transient Cauchy boundary condition (3rd kind) with daily intervals of head extending from the step in the bedrock to the river Rhine (cf. Fig. 1). According to the progression of seasonal temperature measurements near the northwestern model boundary with minor variations (cf. OW 3, Fig. 4), no thermal exchange across this boundary was assumed.

\subsubsection{Southern model boundary}

The southern model boundary was defined as transient Dirichlet boundary condition (1st kind) for head and temperature by including daily interval data from four observation wells (Fig. 1). Temperature data from four observation wells allowed for taking into account several thermal influences such as (a) the densely urbanized area up-gradient of the middle part of the southern model boundary (cf. Fig. 1), (b) the less urbanized area up-gradient of the left side of the southern model boundary and within the southwestern part of the model domain (cf. Fig. 1), and (c) an area with little influence on the native thermal groundwater regime on the right side of the southern model boundary where the thickness of the groundwater saturated zone is comparably small.

\subsubsection{Injection of water with elevated temperatures}

Detailed data of extraction and injection rates/temperatures was only available for one thermal groundwater user (Bürgerspital close to OW 3; Fig. 1). Additionally, two thermal groundwater users with injection of water with an 
assumed average temperature increase of $4 \mathrm{~K}$ (compared to the extracted groundwater temperature; PUK and waste incineration facility) were considered. The locations of extraction and injection were incorporated at the appropriate depths.

Table 2 summarizes the daily average and maximum energy that the three existing thermal groundwater users extracted in 2010 during the operation period in summer. The energy $\left(E_{\mathrm{G}}\right)$ in kilowatts $(\mathrm{kW})$ extracted by the thermal groundwater users can be calculated using the following equation:

$E_{\mathrm{G}}=c_{\mathrm{w}} \times \rho_{\mathrm{w}} \times Q \times \Delta T$,

where $c_{\mathrm{w}}$ is the specific heat of water $\left(\mathrm{kJ} \mathrm{kg}^{-1} \mathrm{~K}^{-1}\right), \rho_{\mathrm{W}}$ the density of water $\left[\mathrm{kg} \mathrm{m}^{-3}\right], Q$ is the flow of water (well yield $\left.\mathrm{m}^{3} \mathrm{~s}^{-1}\right)$, and $\Delta T$ is the temperature reduction or increase in the heat pump $(\mathrm{K})$.

During operation in summer the three thermal groundwater users extract approx. $597 \mathrm{~m}^{3} \mathrm{~d}^{-1}$. With the consideration of water density at $10^{\circ} \mathrm{C}$ of approx. $999.7 \mathrm{~kg} \mathrm{~m}^{-3}$, this results in a nominal geothermal energy extraction $\left(E_{\mathrm{G}}\right)$ of approx. $78 \mathrm{~kW}$ in total.

\subsubsection{Thermal input of heated construction parts reaching into the subsurface (cellars, underground parking lots, etc.)}

To account for the thermal input of heated subsurface constructions, three building types were distinguished: (1) smaller buildings with basement areas ranging between 0 to $2000 \mathrm{~m}^{2}$, which are assumed to reach one storey below ground; (2) larger buildings with basement areas above $2000 \mathrm{~m}^{2}$, which are assumed to reach two storeys below ground (e.g. subterranean parking); and (3) large buildings with a basement areas above $4000 \mathrm{~m}^{2}$, which reach at variable extents into the groundwater; the areal extent and the exact depth could be considered for the model setup. The majority of smaller buildings were built in the first half of the last century with only one basement level. Most of the larger buildings and also of those buildings which reach into the groundwater or to the bedrock can be found in the northern part of the investigated area. According to the depth from the surface to the water table (see above), it can be concluded that the basement of the majority of subsurface constructions lies within the unsaturated zone. In the current model setup, the effect of dissipated heat from the public sewer systems and the district heating network (isolated lines) was not accounted for explicitly. It is assumed that the influence of these structures is locally limited and currently the data are not readily available (network locations and especially depth).

In order to estimate the heat input of building structures into the unsaturated zone, it was assumed that the basement level of smaller buildings lies at around $2.5 \mathrm{~m}$ below ground surface. For the larger buildings it was assumed that they have basement levels of $6 \mathrm{~m}$ below ground surface. From the
Table 2. Energy extracted for cooling by thermal groundwater users for 2010 (see Fig. 1 for locations of thermal users).

\begin{tabular}{|c|c|c|c|}
\hline $\begin{array}{l}\text { Thermal } \\
\text { groundwater } \\
\text { user } \\
\text { (Operation } \\
\text { period } d \text { ) }\end{array}$ & $\begin{array}{l}\text { Well yield } \\
\left(\mathrm{m}^{3} \mathrm{~d}^{-1}\right) \\
\text { Average } \\
\text { (maximum) }\end{array}$ & $\begin{array}{l}\text { Temperature } \\
\text { reduction }(\mathrm{K}) \\
\text { Average } \\
\text { (maximum) }\end{array}$ & $\begin{array}{l}\text { Energy } \\
\text { extracted } \\
(\mathrm{kW}) \\
\text { Average } \\
\text { (maximum) }\end{array}$ \\
\hline $\begin{array}{l}\text { Bürgerspital } \\
(83-318)\end{array}$ & 391 (1002) & 2 (3) measured & $38(126)$ \\
\hline $\begin{array}{l}\text { Implenia AG } \\
(91-334)\end{array}$ & $106(1305)$ & $4^{*}$ & $21(254)$ \\
\hline $\begin{array}{l}\text { PUK } \\
(1-365)\end{array}$ & $100(218)$ & $4^{*}$ & $19(33)$ \\
\hline Sum & $597(2525)$ & - & $78(413)$ \\
\hline
\end{tabular}

* estimated (see text).

length and the area of the respective polygon shapes (Fig. 2) as well as the assumed depth below surface, the surface area in contact with the unsaturated zone could be calculated, which amounts to approx. $2.3 \times 10^{6} \mathrm{~m}^{2}$ for the smaller and to approx. $4.1 \times 10^{5} \mathrm{~m}^{2}$ for the larger buildings. The heat transfer from these constructions to the unsaturated zone was calculated by

$E_{\mathrm{B}}=k \times A \times \Delta T$,

where $k$ is the heat transfer coefficient, $A$ the surface area in contact with the unsaturated zone and $\Delta T$ the temperature difference between the subsurface constructions and the unsaturated zone. As the degree of building isolation in Basel should be comparably high, a heat transfer coefficient of $0.3 \mathrm{~W} \mathrm{~m}^{-2} \mathrm{~K}^{-1}$ was considered. For the subsurface constructions a constant temperature of $15^{\circ} \mathrm{C}$ was assumed and for the unsaturated zone data time series of soil temperatures in 1.9 and $4.7 \mathrm{~m}$ depth (average effective depth of the smaller and larger subsurface constructions, respectively, under a proportional consideration of the side wall and basement area) were derived by Baehr and Stephan (2006):

$$
\begin{aligned}
& T(z, t)=T_{0 \mathrm{~m}}+\Delta T \cdot e^{-\frac{2 \pi z}{\Lambda}} \cos \left(2 \pi\left(\frac{t}{t_{0}}-\frac{z}{\Lambda}\right)\right), \\
& \Lambda=2 \sqrt{\pi \alpha t_{0}},
\end{aligned}
$$

with soil temperature $T(z, t)$ at depth $z$ and time $t, T_{\mathrm{m}}$ mean yearly soil surface temperature $\left(12,12^{\circ} \mathrm{C}\right), \Delta T$ amplitude of soil surface temperature $\left(12^{\circ} \mathrm{C}\right), t_{0}$ as period length ( $365 \mathrm{~d}), \alpha$ is thermal diffusivity $\left(2.69 \times 10^{-3} \mathrm{~m} \mathrm{~s}^{-1}\right)$ and $\Lambda$ is the wavelength of one oscillation of temperature fluctuations. Figure 2 summarizes the resulting cumulative heat transfer between the subsurface constructions and the unsaturated zone. With a retarded maximum of above $5 \mathrm{MW}$, heat is transferred in winter and spring from the subsurface constructions to the unsaturated zone. In late summer heat 
transfer is from the unsaturated zone to the subsurface constructions. The calculations give an idea about orders of magnitude which have to be expected for the heat transfer between subsurface constructions and the unsaturated zone.

For the integration of this heat flux within the heat transport model: in a first step two groups of polygons were delineated (excluding larger open space areas), the first group contains most of the smaller buildings within the investigation area and the second group contains the larger buildings mostly located within the northern investigation area (Fig. 2). In a next step the heat flux input for model layers 1 (smaller buildings) and 2 (larger buildings) was calibrated until the results of the analytical calculations almost matched the modeled ones (Fig. 2).

Large buildings (base area $>4000 \mathrm{~m}^{2}$ ) with construction parts reaching into the groundwater (Fig. 2) mainly comprise subsurface premises which are used as workplaces (e.g. laboratories) and are assumed to be heated to temperatures in the order of $20^{\circ} \mathrm{C}$ (see above). For the heat flux of these buildings, Eq. (2) was used by incorporating the surface area in contact with the saturated zone, the temperature difference between $20^{\circ} \mathrm{C}$ and the measured groundwater temperature in the inflow of the northern industrial area (OW 6; Fig. 2) as well as a heat transfer coefficient of $0.3 \mathrm{~W} \mathrm{~m}^{-2} \mathrm{~K}^{-1}$ (see above).

\subsection{Evaluation of exploitation and urbanization scenarios}

The calibrated regional heat transport model was used for two sets of exploitation and urbanization scenarios. The first set of scenarios encompasses additional groundwater use for cooling purposes and future urbanization. The scenarios focus on the simulation of: (A) new thermal groundwater use up-gradient of an existing thermal groundwater user and the evaluation of the interference of the existing and new thermal groundwater use; and (B) urbanization and new buildingparts that reach into the subsurface according to available information on development plans. The second set of scenarios deals with the compensation of past thermal influences on the thermal groundwater regime in the investigation area. Therefore, targeted new groundwater use for heating to reduce groundwater temperatures down-gradient are introduced in two different zones of the aquifer (zone B and C, Fig. 1). In order to evaluate the long-term thermal impact, the 2010 data set and scenario modifications were included cyclic for a time period of $10 \mathrm{yr}$.

\section{Results}

\subsection{Monitoring results - short- and long-term variation of groundwater temperatures}

Analyses of groundwater temperature data demonstrate a variable annual range of groundwater temperatures and a maximum variability of up to $3 \mathrm{~K}$. The variation in measured temperature data is the combined result of (1) heat transport from the ground surface by conduction as well as by convection with water infiltrating through the unsaturated zone and into the saturated porous medium, (2) river-groundwater interaction, as well as (3) thermal influence of thermal groundwater users and urbanization.

Figure 4 shows selected short- and long-term time series of groundwater temperature measurements. The data show that numerous observation wells measure a temperature maximum in autumn to spring which can be explained by heating periods (e.g. OW 1). Generally, high groundwater temperatures are attributed to the diffuse influence of urbanization and heated buildings parts in the subsurface and in the groundwater as well as thermal groundwater use (e.g. OW 2). In less urbanized areas, groundwater temperatures are comparably low and show little variation throughout the year (e.g. OW 3). The data analysis of long-term temperature development show that changes within seasonal cycles can be observed for several observation wells (e.g. OW 4). Several temperature time series show a positive trend (e.g. OW 3). Some observation wells show a continuous rising of temperatures, which may be attributed to a retarded influence of construction development (e.g. OW 5).

\subsection{Monitoring results - high-resolution multilevel temperature monitoring}

Figure 5 shows the temperature time series of the highresolution multilevel observation wells as contour lines. For the contour plots time series of a nearby conventional observation well were included (Fig. 1).

As a result of anthropogenic influences in all four wells, considerably high groundwater temperatures can be observed which, in densely urbanized areas (e.g. well III), can almost reach $17^{\circ} \mathrm{C}$. Temperature distributions are very heterogeneous and preferential thermal propagation is intensified within more conductive coarse fluvial deposits. Maximum temperatures generally are measured between December and April. Different timing and time spans of seasonal elevated temperatures indicate direct influence of heating periods and retardation processes. In observation wells I and II, maximum temperatures at the bottom of the aquifer to 2.3 and $1.2 \mathrm{~m}$ above the bedrock, respectively, are measured in July. The timing of minimum temperatures is more complex. In several wells minimum temperatures are measured between the heating periods (e.g. well IV). Some observation wells show atmospheric influences in the unsaturated zone (e.g. well II). The thermal memory effect is revealed by the retardation of thermal plumes as the seasonal shift of elevated temperatures resulting from heating periods (all four wells) or as a response of groundwater temperatures after flood events (only well I). Generally, the measured temperatures in all four multilevel observations wells are about $1{ }^{\circ} \mathrm{C}$ cooler than those measured in conventional 

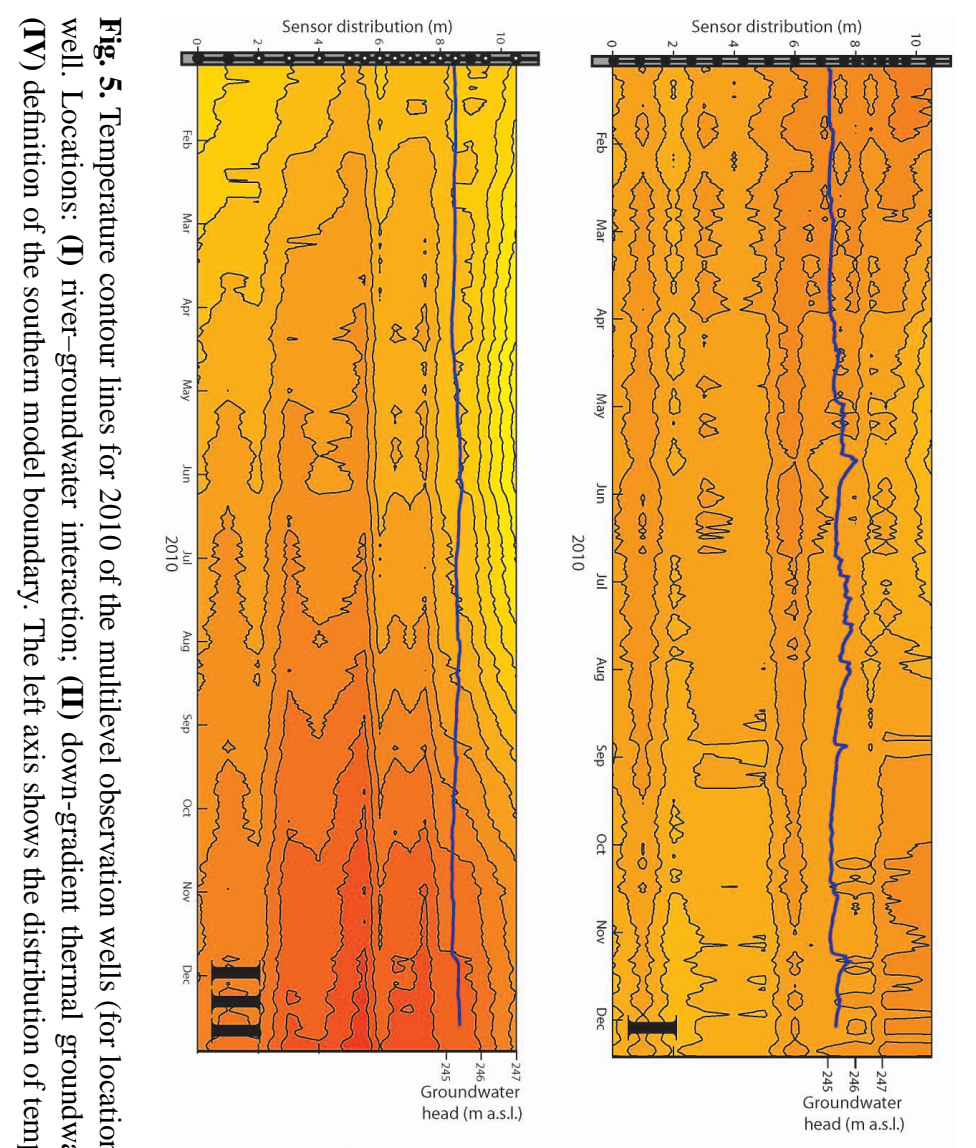

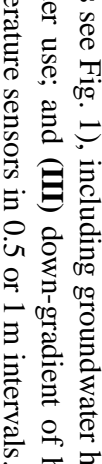

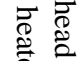

$\stackrel{\overrightarrow{8}}{2}$

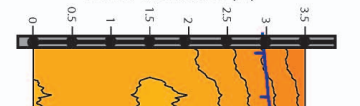

Sensor distributio $(\mathrm{m})$
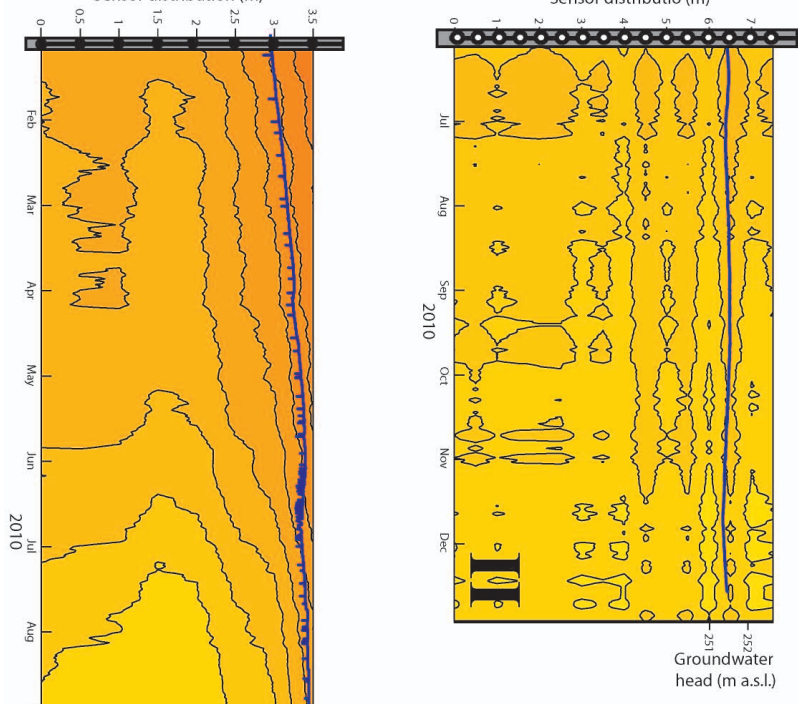

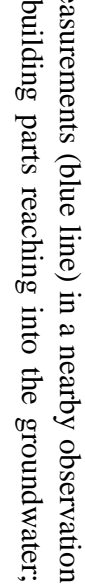
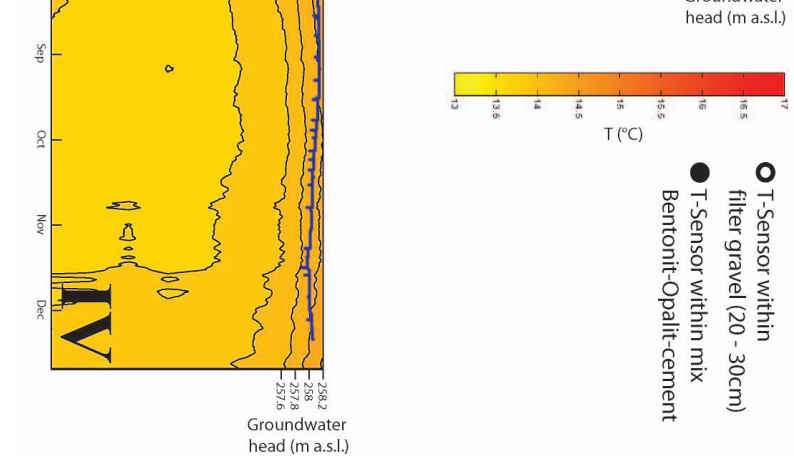

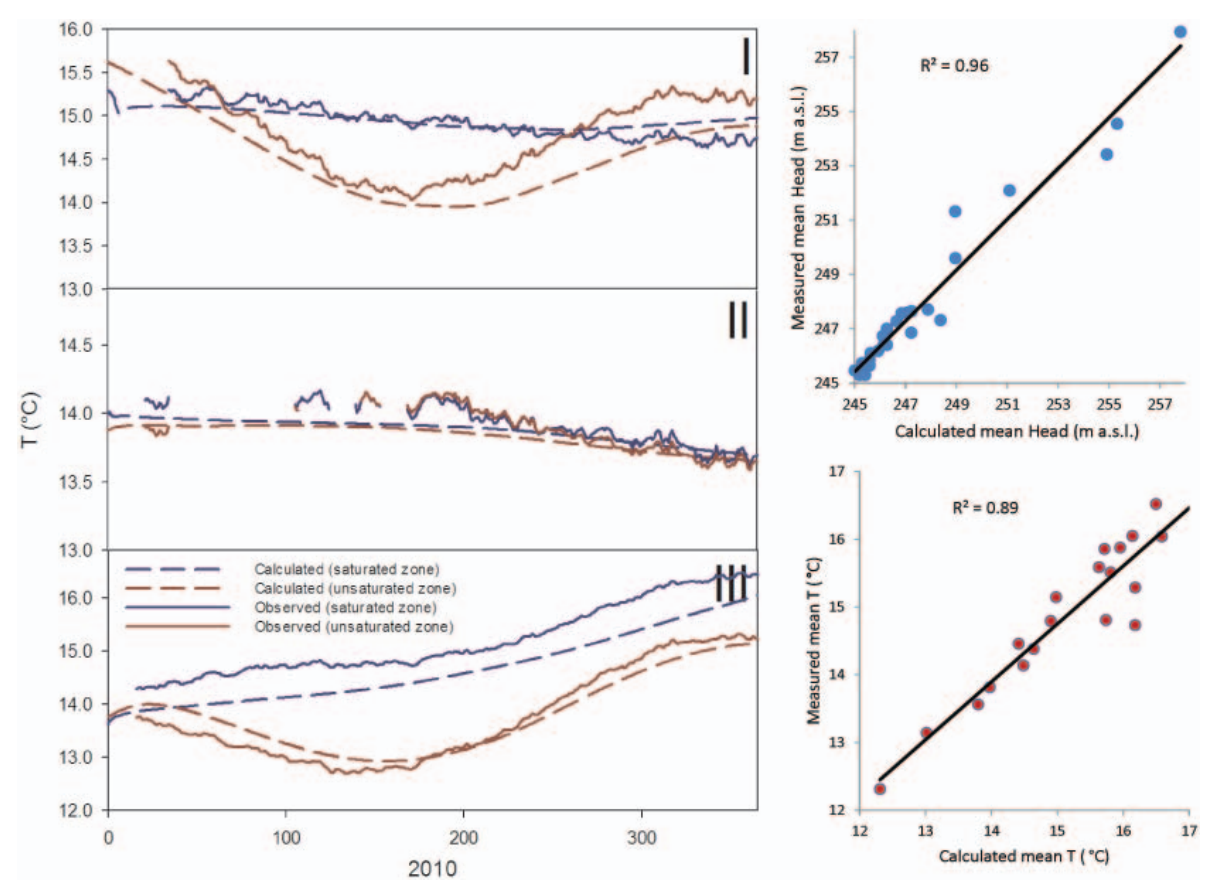

Fig. 6. Left panels: calibration results for the local 2-D and 3-D heat transport models at the locations of multilevel groundwater observation wells I-III (for locations see Fig. 1). Right panels: calibration results for the regional 3-D heat transport model.

observation wells nearby (Fig. 1). This temperature deviation might be explained by thermal convection processes within the air filled measuring tubes of the conventional observation wells. In some observation wells the transfer from the unsaturated to the saturated zone can be detected.

A thermal stratification was only observable in the southern observation well IV, where less natural and anthropogenic disturbance occurs. As for the remaining multilevel observation wells, no vertical thermal stratification within the groundwater saturated zone can be observed. Classical tautochrones which describe the seasonal penetration of temperature fluctuation by subsurface temperature profiles (Fig. 3; Taylor and Stefan, 2009; Yamano et al., 2009) are not applicable for groundwater saturated zones within heterogeneous gravel aquifers where high groundwater flow velocities can be observed and which are covered by a thick unsaturated zone. Here, advective heat transport dominates thermal groundwater regimes and preferential thermal propagation is very heterogeneous and intensified in more conductive coarse fluvial deposits.

\subsection{Results of heat transport modeling}

With the local 2-D and 3-D heat transport models, a very good agreement of calculated and observed hydraulic (conventional observation wells) and temperature data within the saturated and unsaturated zone (multilevel observation wells) could be established (Fig. 6). Therefore, it can be assumed that the models can reproduce the local heat transport processes in general and also in vertical direction regarding the interaction of the atmosphere, the unsaturated and the saturated zone.

Figure 6 also shows the calibration results for the regional 3 -D heat transport model. The observed and calculated temperatures as well as head data are in good to very good agreement. The heat input of building structures located within the unsaturated zone of the heat transport model was calibrated according to the results of an analytical solution (see above). Figure 2 shows the resulting cumulative heat transfer between the subsurface constructions and the unsaturated zone. With a retarded maximum of above $5 \mathrm{MW}$, heat is transferred in winter and spring from the subsurface constructions to the unsaturated zone. In late summer heat transfer is from the unsaturated zone to the subsurface constructions.

Groundwater exfiltrating into the river Rhine amounts to annually $1.9 \times 10^{6} \mathrm{~m}^{3}$. River water infiltrating from the river Rhine into the groundwater amounts to annually $1.7 \times 10^{5} \mathrm{~m}^{3}$. Hence, apart from flood events, exfiltration of groundwater into the river Rhine is the dominating exchange process.

\subsubsection{Thermal influence of the unsaturated zone}

In order to evaluate the importance of the upper and the regional thermal boundary condition for the local models, the cumulated heat flux budgets for the year 2010 across these model boundaries was calculated and standardized to a unit length of $1 \mathrm{~m}$ (Fig. 3). 


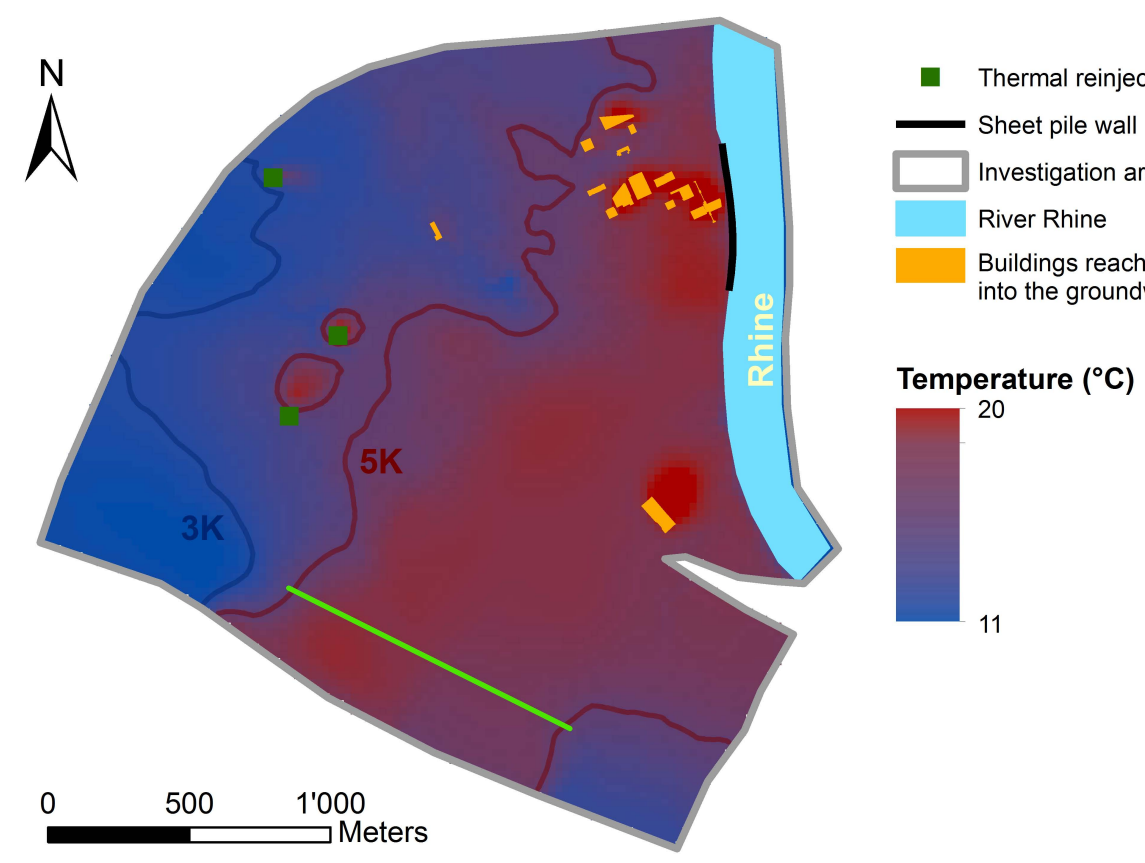

Fig. 7. Calculated temperature distribution for 31 December 2010 in model layer 11. Delineation of areas with temperature increases of $<3 \mathrm{~K}$ as well as $>5 \mathrm{~K}$ compared to a "potential natural" state (for explanation refer to the text). Water budgets were calculated through the green zone.

The inflow accounting for the regional thermal advective transport is one order of magnitude higher compared to the inflow across the upper boundary condition representing the atmospheric influence. Additionally, it should be considered that high input and output values are arising from strong gradients within the unsaturated zone due to seasonal temperature fluctuation at the soil surface. These fluctuations decrease rapidly with increasing depth below surface (Fig. 3). The calculated temperature tautochrones at the location of all three multilevel observation wells show that seasonal temperature variations are virtually dampened before reaching the saturated aquifer. Consequently, the heat transfer through the unsaturated zone into the saturated zone is significantly lower compared to the calculated heat flux budget at the soil surface. Therefore, it can be concluded for the investigated groundwater body that, in consideration of the comparably large depth from the surface to the groundwater table (mean $19 \mathrm{~m}$; Fig. 1), the influence of the heat flux through the unsaturated zone is low compared to the regional thermal advective transport.

\subsubsection{Thermal groundwater regimes "present state 2010"}

Figure 7 shows the groundwater thermal regime for 31 December 2010 in model layer 11. The influence of the urbanized area resulting in elevated temperatures is distinct. Down-gradient of three thermal groundwater users, the effect of injected water with elevated temperatures can be observed.
In the southern part of the model area, the following thermal influences can be observed: (a) elevated groundwater temperatures originating from the densely urbanized area in the south (cf. Fig. 1); (b) reduced groundwater temperatures in the southwestern less urbanized areas (cf. Fig. 1); and (c) reduced groundwater temperatures in the southeastern model area where the thickness of the groundwater saturated zone is small. Comparable low temperatures originate from the western model boundary for less urbanized areas. The effect of the heated buildings within the groundwater body can be observed. In the entire northern industrial area (zone C, cf. Fig. 1), elevated temperatures are observable which can be attributed to the low flow velocities in this area.

Figure 8 shows the cumulative heat fluxes calculated for the "natural" and "anthropogenic" model boundaries for 2010. The highest energy exchange with $4.3 \times 10^{3} \mathrm{MW}$ occurs at the top model layer. However, the thermal influence is balanced throughout the year and comparably low within the saturated zone (see above). Thermal advective transport is controlled by the southern and the river boundaries, which are balanced throughout the year. The influence of the basal heat flux is negligible. However, the consideration of a $20 \mathrm{~m}$ thick layer below the alluvial gravel deposits facilitates to account for heat storage processes in the underlying consolidated layer. As a result, seasonal and anthropogenic temperature fluctuations are damped and the difference between calculated and observed temperature time curves are reduced compared to preceding model runs. The heat fluxes 

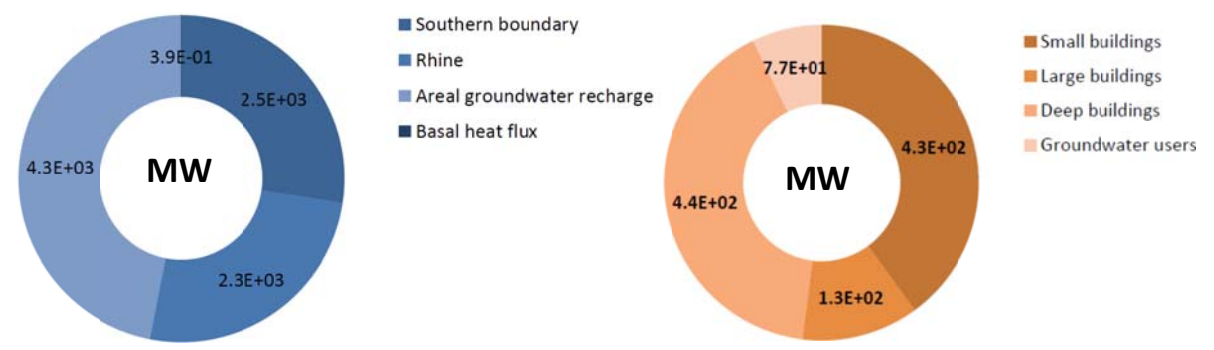

Fig. 8. Cumulative heat fluxes for 2010. Left panel: heat fluxes of natural boundaries (the influence of the basal heat flux is negligible). Right panel: heat fluxes of anthropogenic boundaries.

calculated for the anthropogenic model boundaries are not balanced and are discussed below.

\subsubsection{Thermal influence of heated buildings}

Figure 8 shows the cumulative heat fluxes calculated for the anthropogenic model boundaries for 2010, including the different building types. The calculated heat flux from small and large buildings within the unsaturated zone as well as heated buildings reaching into the saturated zone amount to $4.3 \times 10^{2}, 1.3 \times 10^{2}$ and $4.4 \times 10^{2} \mathrm{MW}$; respectively. Normalized heat flux per $\mathrm{m}^{2}$ results in approx. $1.8 \times 10^{-1} \mathrm{~W} \mathrm{~m}^{-2}$ for the small buildings $\left(2.3 \times 10^{6} \mathrm{~m}^{2}\right)$, to approx. $3.0 \times 10^{-11} \mathrm{~W} \mathrm{~m}^{-2}\left(4.1 \times 10^{5} \mathrm{~m}^{2}\right)$ for the large buildings located within the unsaturated zone and to approx. $16 \mathrm{~W} \mathrm{~m}^{-2}\left(2.8 \times 10^{4} \mathrm{~m}^{2}\right)$ for those buildings reaching into the saturated zone. Therefore, relative heat loss of building structures within the saturated zone is considerably higher compared to heat loss of building structures within the unsaturated zone. This finding is in agreement with Dahlem and Heinrich (1999) and Dahlem (2000) who evaluated the influence of heat loss of building structures within the saturated zone. They found that heat loss due to advective groundwater flow can be in the order of 10 times higher compared to solely conductive heat loss.

\subsubsection{Thermal influence of groundwater use}

Figure 8 shows the cumulative heat flux of a total $77 \mathrm{MW}$, which can be assigned to groundwater use in the investigation area for 2010. The total flux into the groundwater body amounts to $67 \mathrm{MW}$ and can be assigned to the injection of water with elevated temperatures. The total flux out of the groundwater body amounts to $10 \mathrm{MW}$.

The thermal influence of groundwater use for cooling purposes in the investigation area is exemplary illustrated for two thermal groundwater users, the "Bürgerspital" (located near OW 3, Fig. 1) and the "Implenia AG" (located upgradient of multilevel observation well II, Fig. 1).

For the thermal groundwater user Bürgerspital, highresolution extraction/injection groundwater rates and temperatures were available. The average calculated injected heat for the operation period 2010 (cf. Table 2) amounts to $48 \mathrm{~kW}$, which is slightly higher compared to the calculated value in Table 2 .

Up-gradient of the injection of the thermal groundwater user Implenia AG, the measured average groundwater temperatures at the location of the extraction amount to $14.9{ }^{\circ} \mathrm{C}$. It was assumed that an average increase of the thermally used water is in the order of $4 \mathrm{~K}$, which results in approx. $19^{\circ} \mathrm{C}$ for the injected water (Table 2). The average calculated injected heat for the operation period 2010 (cf. Table 2) amounts to $28 \mathrm{~kW}$, which is slightly higher compared to the calculated value in Table 2.

\subsection{Results of scenario calculations}

The derivation of a "potential natural state" under undisturbed (pre-exploitation) conditions and the evaluation of the "influence of climate change" are covered in Epting and Huggenberger (2013). The results of this work illustrate how the thermal groundwater regime developed before major urbanization of the region and without thermal groundwater use: "The calibrated "present state" model (2010) served as a baseline for scenario calculations. To obtain a "potential natural state" all anthropogenic boundary conditions were removed from the "present state" model (2010), leaving only the natural boundaries (atmosphere, including groundwater recharge and surface temperatures; the River Rhine, including river head and surface water temperatures; as well as the basal heat flux). The "potential natural state" represents the thermal groundwater regime under undisturbed (pre-exploitation) conditions and is comparable to the situation in undisturbed regions outside of the city". The comparison of the modeling results from 2010 ("present state") with the "potential natural state" of the groundwater thermal regime allowed us to illustrate how the different regions of the investigated GWB are already effected by temperature increases.

\subsubsection{New thermal groundwater use}

Figure 9 shows the thermal influence down-gradient of a new thermal groundwater user and within the inflow area of the groundwater user Bürgerspital (Fig. 1). Groundwater temperatures down-gradient rise to values of up to $18^{\circ} \mathrm{C}$ 


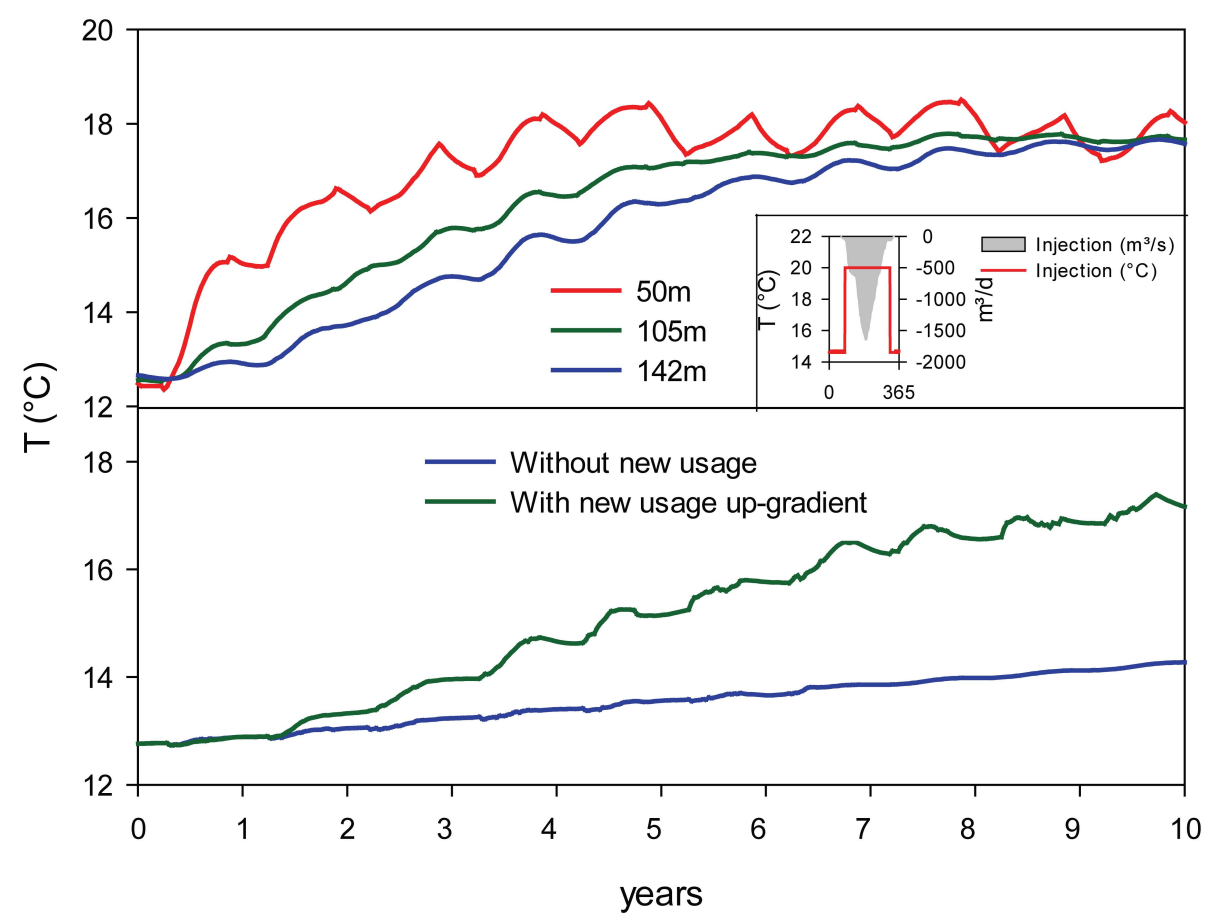

Fig. 9. Simulation of new thermal groundwater use up-gradient of the groundwater user Bürgerspital who uses the extracted groundwater for cooling purposes (for locations see Fig. 1). Upper panel: thermal influence down-gradient of the new thermal groundwater user (imbedded subplot: simulated extraction and injection rates as well as temperatures of the injected water). Bottom panel: influence of the new thermal groundwater use on the thermal groundwater user Bürgerspital.

in approx. $50 \mathrm{~m}$ distance and up to $17^{\circ} \mathrm{C}$ in approx. $140 \mathrm{~m}$ distance. Figure 9 also shows the thermal influence on the thermal use of the Bürgerspital, where the temperature of extracted groundwater might rise above $16^{\circ} \mathrm{C}$. The positive trend observed in the bottom panel for the time series without new usage can be attributed to the progressive heating input of building structures within the inflow area (cf. OW 3 and OW 5 in Fig. 4).

\subsubsection{Future urbanization}

Figure 1 shows the locations for which new buildings with structures reaching into the subsurface were evaluated. In order to evaluate an intermediate urbanization scenario, only large building structures reaching into the unsaturated zone were considered. Figure 10 shows the resulting groundwater thermal regimes for winter 2010/2011. The influence of future urbanization results in a further extension of areas with elevated temperatures.

\subsection{Potential for future thermal groundwater use within the investigated GWB}

\subsection{1 "Cooling"}

The Swiss Guidelines on Water Protection (GSchV, 2001) permits temperature differences down-gradient of thermal groundwater use of $3 \mathrm{~K}$. Figure 7 shows where in the investigated GWB current groundwater temperatures have increased less than $3 \mathrm{~K}$, compared to a potential natural state. In regard to the small size of the remaining areas and a minimum degree of efficiency discussed above, only limited potential for future thermal groundwater use for cooling purposes exists. The rest of the investigated GWB already shows temperature increases that, after the Swiss regulations, would not permit further use.

\subsection{2 "Heating"}

On the other hand, the already elevated groundwater temperatures could be used for heat extraction (Gringarten and Sauty, 1975). The calculated volumetric total heat energy within the anthropogenic influenced aquifer amounts to $85 \mathrm{MW}$ for the year 2010. In comparison, calculated yearly energy fluxes within the potential natural aquifer amounts to only $44 \mathrm{MW}$. Hence, within the anthropogenic influenced aquifer, additional energy fluxes amount to $41 \mathrm{MW}$. The additional energy fluxes derive from anthropogenic sources as heated buildings (cf. Fig. 8) would mostly be existent in the future and could be exploited long-term.

The following assumptions were made for the potential use of the urban GWB for heating: as only elevated groundwater temperatures are observed in the investigated GWB, according to Swiss Guidelines on Water Protection (GSchV, 


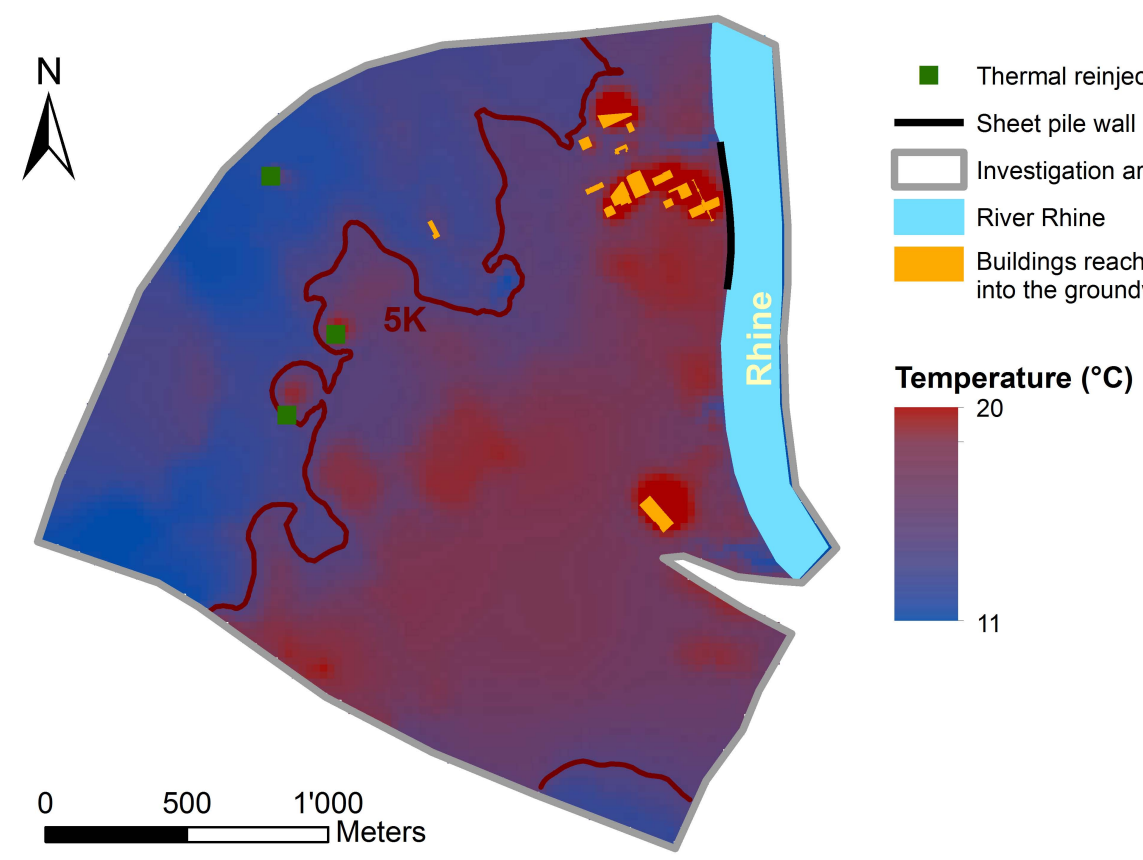

Fig. 10. Calculated temperature distribution for winter 2010/2011 under consideration of future urbanization (for locations see Fig. 1). Delineation of areas with temperature increases $>5 \mathrm{~K}$ compared to a "potential natural" state (for explanation refer to the text).

2001), practically everywhere temperature reductions of up to $3 \mathrm{~K}$ down-gradient of thermal groundwater use would be feasible. Figure 7 illustrates the potential for future thermal groundwater use (heating) for the investigated GWB and an area with already observed temperature increases of more than $5 \mathrm{~K}$. Other important factors to be considered are flow budgets, which were calculated through a zone of the designated area and amount to $800 \mathrm{~m}^{3} \mathrm{~d}^{-1}$. Assuming a heat extraction of $5 \mathrm{~K}$ (difference of current to potential natural temperatures) or $8 \mathrm{~K}$ (difference of current to potential natural temperatures plus permitted temperature increase of $3 \mathrm{~K}$ ) would result in nominal geothermal heating resources of $194 \mathrm{KW}$ and $311 \mathrm{KW}$, respectively. Figure 11 shows the results of scenarios that are based on new thermal groundwater use for heating purposes in zone B (Fig. 1). A first scenario considers only one well doublet; a second scenario considers a gallery of 4 well doublets within the southern inflow area. For the simulation a temperature of the injected water of $10^{\circ} \mathrm{C}$ was considered. The calculated temperature distributions illustrate the long-term development of temperatures down-gradient of the injection after $10 \mathrm{yr}$. Figure 12 shows the thermal influence down-gradient of the injection of the single well doublet along two down-gradient mesh nodes on a streamline. In $217 \mathrm{~m}$ distance of the injection after approx. $7 \mathrm{yr}$, a new thermal equilibrium can be observed with temperatures ranging between 12.5 and $13{ }^{\circ} \mathrm{C}$. However, in $426 \mathrm{~m}$ distance no influence can be observed. With only one well doublet, the cooling influence down-gradient of the thermal reinjection well is relatively local. The operation of a gallery of four thermal reinjection wells would result in an expanded cooling influence down-gradient.

Figure 12 also shows the results of a scenario that is based on new thermal groundwater use for heating purposes in zone $\mathrm{C}$ (Fig. 1) together with the location of the extraction and injection well. For the simulation a calculated extraction and reinjection flow budget of $460 \mathrm{~m}^{3} \mathrm{~d}^{-1}$ and a temperature of the injected water of $10^{\circ} \mathrm{C}$ were considered. The calculated temperature distributions illustrate that, because of the high density of heated buildings reaching into the aquifer even under the consideration of a long-term development, groundwater temperatures in zone $\mathrm{C}$ are only locally reduced to temperatures between 11 and $12^{\circ} \mathrm{C}$. Figure 12 shows the thermal influence down-gradient of the injection along two down-gradient mesh nodes on a streamline. Already after less than $5 \mathrm{yr}$ a new thermal equilibrium can be observed in $130 \mathrm{~m}$ (temperature range between 12 and $13^{\circ} \mathrm{C}$ ) and $330 \mathrm{~m}$ (temperature range between 14 and $14.5^{\circ} \mathrm{C}$ ).

\section{Discussion}

The presented data allow for a comparison of short- and longterm measured temperature data with modeled groundwater temperatures for the year 2010. Results of the multilevel temperature monitoring improved the interpretation of existing temperature measurements within the investigation area. The datasets also allowed for a calibration of high resolution 3D numerical coupled groundwater flow and heat transport models. As a result, seasonal and anthropogenic influences 

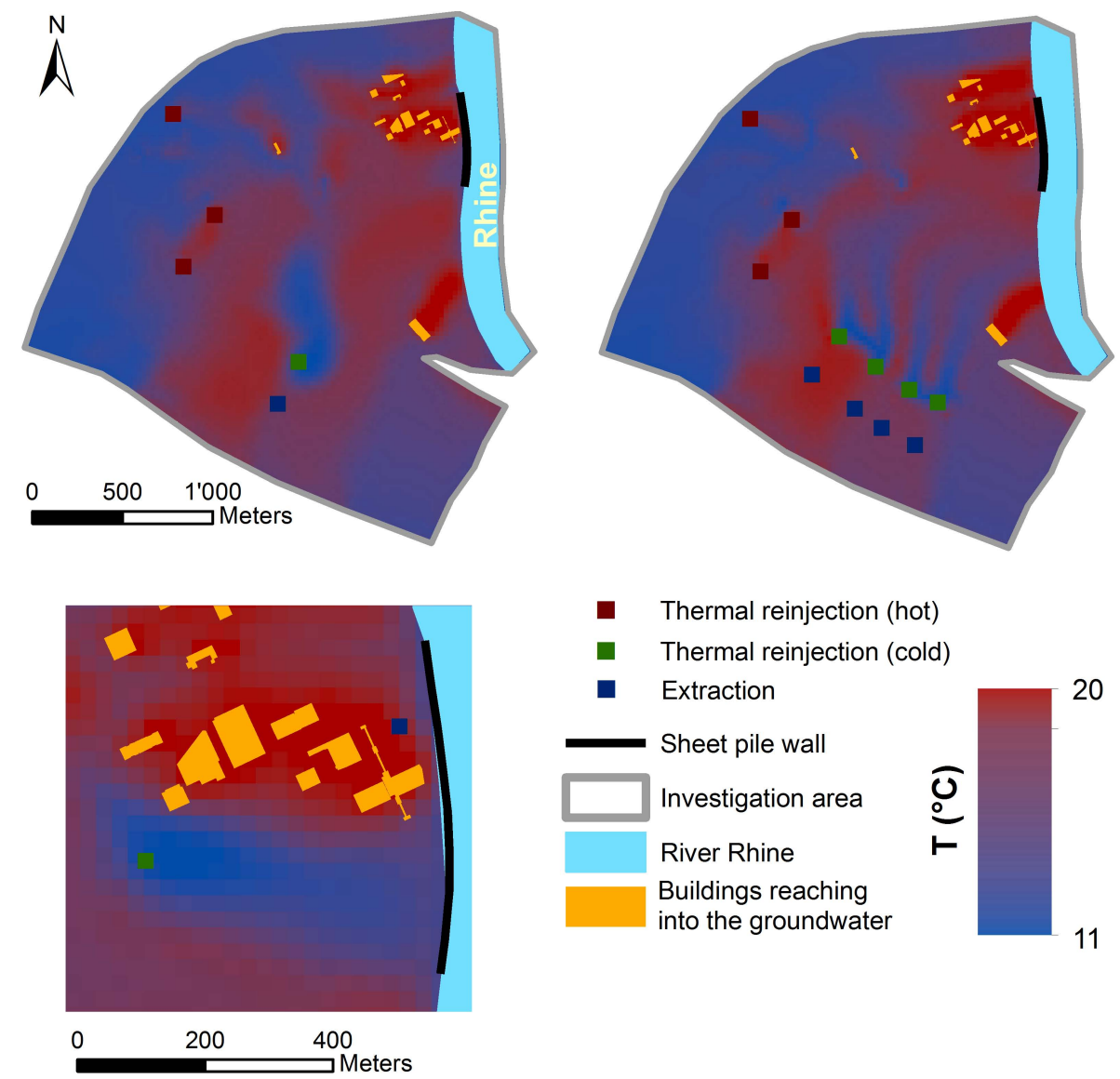

Fig. 11. Calculated temperature distribution after $10 \mathrm{yr}$ for scenarios of new groundwater use for heating (for locations see Fig. 1). Upper left panel: new groundwater use within the southern inflow area (zone B); upper right panel: gallery of new groundwater use for heating within the southern inflow area (zone B); and bottom left panel: new groundwater use for heating within the northern industrial area (zone C).

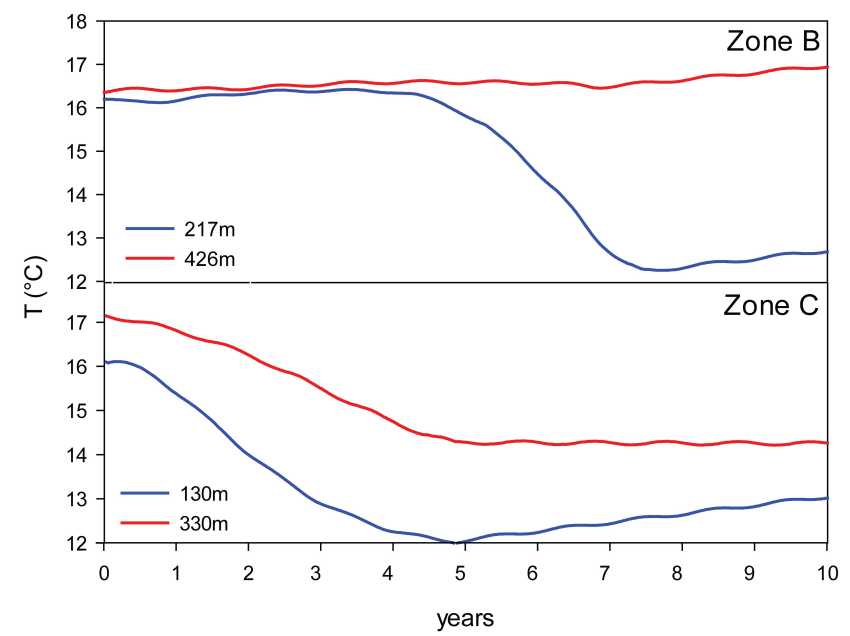

Fig. 12. Development of temperatures down-gradient of new groundwater use for heating for zones B and C (for locations see Figs. 1 and 11). on the temperature regime of the urban GWB in the Basel area could be distinguished.

Furthermore, no direct influence of seasonal thermal regimes originating from the ground surface could be observed within the groundwater saturated zones. Moreover, natural and anthropogenic disturbances seem to dominate thermal groundwater regimes within the heterogeneous gravel aquifer where high groundwater flow velocities are observed. Preferential thermal propagation is very heterogeneous and intensified in more conductive coarse fluvial deposits.

\subsection{Effects of boundary conditions}

Thermal groundwater use, together with the increasing number of heated buildings that reach into the unsaturated and saturated zone and the long-term positive trend of air and river temperatures, make subsurface temperatures in the urban area of Basel higher than in the surrounding rural areas. 
Apart from major flood events, exfiltration of groundwater into the river Rhine is the dominating river-groundwater interaction process. Therefore, the influence of advective thermal transport of infiltrating river water into the aquifer plays a minor role compared to the remaining thermal boundary conditions.

Heat loss from buildings is having a noticeable influence on the distribution of subsurface temperatures in Basel. The resulting distribution of temperatures is dependent on the following factors: (1) the historical duration of heat loading, (2) the distance from a given measurement point to a building, and (3) the density of buildings in the given area. In spring after the heating period down-gradient of heated buildings, an annual groundwater temperature maximum can be observed. The numerical simulation of heat loss from temperature-controlled buildings could be used to predict the resulting subsurface temperature field down-gradient.

Another major thermal input to urban GWBs originates from thermal groundwater users who use groundwater for cooling purposes. Especially in summer down-gradient of thermal groundwater users, an annual temperature maximum within the groundwater can be observed. The numerical simulation can be used to predict the resulting subsurface temperature field down-gradient.

Whereas the main natural and anthropogenic impacts on the thermal groundwater regime of the GWB in the Basel area could be reproduced with the performed modeling approach, in future modeling results could be improved by (1) recording groundwater extraction and reinjection quantities and temperatures for thermal groundwater use at least on a daily basis; (2) conducting further investigations of the effects of subsurface construction, including the sewage network, within the unsaturated zone; and (3) investigating heat transport by defining thermofacies within the heterogeneous aquifer and evaluating the potential for aquifer thermal energy storage (Bridger and Allen, 2010).

\subsection{Implications for urban groundwater management}

The now available tools allow for optimizing new locations for thermal groundwater use and urbanization (dimensioning and site evaluation of extraction and injection locations, spatial optimal integration into existing supply networks and consideration of subsurface infrastructures), considering long- and medium-term development as well as groundwater management programs (operation schedules, temporal optimal organization of extraction and injection of groundwater).

The results from the investigated GWB allowed for providing guidelines and a suitability map for geothermal subsurface use to the authorities. The suitability maps provide information on different zones within the urban GWB, where recommendations can be formulated as to what extent groundwater can be quantitatively or qualitatively used.

For the urban area of Basel, the use of groundwater for heating purposes would offer an alternative of resource exploitation. Thereby, shallow systems could be used for cooling and deeper systems for heating (i.e. seasonal storage of heat in deeper geological low permeable formations up to $400 \mathrm{~m}$ below the unconsolidated sediments). These strategies could allow compensating past and future thermal influence from urban development (Nakayama and Hashimoto, 2011) and climate change. Sustainability and uncertainties of groundwater-source heating and cooling projects, which are highly dependent on local geological conditions and the configuration of the abstraction and recharge boreholes, could be assessed by predictive and stochastic modeling approaches (Ferguson and Woodbury, 2005; Gandy et al., 2010; Ferguson, 2012).

Such sustainable solutions should also include the provision of legal frameworks on the isolation of subsurface buildings and, in cases of new thermal groundwater use, the application of balanced heating and cooling facilities. Considering future industrial development within the area, the implementation of balanced heating and cooling facilities could be more effective in finding local solutions than changing aquifer use policies for an entire region.

\section{Conclusions}

Thermal groundwater use and the injection of water with elevated or decreased temperatures, heated buildings reaching into the aquifer and river-groundwater interactions inevitably leave their fingerprints on urban groundwater bodies. The various thermal fingerprints persist within the aquifer with characteristic extensions and life spans resulting in a memory effect of the aquifer. To study the influence of the various thermal fingerprints and memory effects, the past and future thermal development of urban groundwater bodies has to be assessed for different timescales.

For the sustainable development of urban subsurface resources, adequate management concepts are required. This includes the setup of tools that enable the investigation of the relevant processes that dominate groundwater flow and thermal regimes at different spatiotemporal scales. The extensive use of geothermal technologies is still limited, mainly because of a lack of information on the advantages and uncertainties of possible long-term environmental effects.

This study illustrates a conceptual approach and the development of tools necessary for the thermal management of a shallow aquifer within high permeable unconsolidated gravel deposits in the Basel area. Results allow localizing and quantifying the main heat sources within the investigated groundwater body, including the impact of thermal groundwater use and buildings constructed into the unsaturated and saturated zone. The identification of areas with elevated temperatures within the groundwater body is the basis for the development and evaluation of future use scenarios and mitigation strategies in regard to groundwater quality and climate change issues. Furthermore, the now available tools allow for 
visualizing the effect of "thermal pollution" and contributing to the debate on the potential use of "wasted energy" in urbanized areas.

Acknowledgements. We thank the AUE BS and Stefan Wiesmeier for their cooperation throughout the scope of this project as well as Rebecca Page for language editing the manuscript. Furthermore, the authors also would like to acknowledge the valuable comments of the reviewers James Constantz, Grant Ferguson and an anonymous reviewer. Thanks go to Harrie-Jan Hendricks Franssen for handling the review process. This work was partially supported by the collaborative research project ANGUS+, BMBF grant 03EK3022B.

Edited by: H.-J. Hendricks Franssen

\section{References}

Allen, A., Milenic, D., and Sikora, P.: Shallow gravel aquifers and the urban "heat island" effect: a source of low enthalpy geothermal energy, Geothermics, 32, 569-578, doi:10.1016/S03756505(03)00063-4, 2003.

Ampofo, F., Maidment, G. G., and Missenden, J. F.: Review of groundwater cooling systems in London, Appl. Therm. Eng., 26, 2055-2062, doi:10.1016/j.applthermaleng.2006.02.013, 2006.

Baehr, H. D. and Stephan, K.: Heat and Mass Transfer, second edition Springer, Berlin, Heidelberg, New York, 2006.

Banks, D.: Thermogeological assessment of open-loop well-doublet schemes: a review and synthesis of analytical approaches, Hydrogeol. J., 17, 1149-1155, doi:10.1007/s10040-008-0427-6, 2009.

Bonte, M., Stuyfzand, P. J., Hulsmann, A., and Van Beelen, P.: Underground Thermal Energy Storage: Environmental Risks and Policy Developments in the Netherlands and European Union, Ecology \& Society, Vol. 16, Special section p1, 2011.

Bridger, D. W. and Allen, D. M.: Heat transport simulations in a heterogeneous aquifer used for aquifer thermal energy storage (ATES), Can. Geotech. J., 47, 96-115, doi:10.1139/T09-078, 2010.

CEC - C. o. t. E. C.: Directive of the European Parliament and of the Council establishing a framework for Community action in the field of water policy: Joint text approved by the Conciliation Committee, 1997/0067(COD), C5-0347/00, The European Parliament, Brussels, 2000.

Clarkson, M. H., Birks, D., Younger, P. L., Carter, A., and Cone, S.: Groundwater cooling at the Royal Festival Hall, London, Q. J. Eng. Geol. Hydro., 42, 335-346, doi:10.1144/1470-9236/08080, 2009.

Constantz, J.: Interaction between stream temperature, streamflow, and groundwater exchanges in Alpine streams, Water Resour. Res., 34, 1609-1615, 1998.

Dahlem, K.-H.: The effect of groundwater on the heat loss of building parts in contact with ground, $\mathrm{PhD}$, Bauphysik/Technische Gebäudeausrüstung/Baulicher Brandschutz, Kaiserslautern, Kaiserslautern, 2000.
Dahlem, K.-H. and Heinrich, H.: Einfluss des Grundwassers auf den Wärmeverlust beheizter Keller, Universität Kaiserslautern, 1999.

Diersch, H. J. G.: FEFLOW Reference Manual, Institute for Water Resources Planning and Systems Research Ltd., Berlin, Germany, 2002.

Epting, J. and Huggenberger, P.: Unraveling the heat island effect observed in urban groundwater bodies, J. Hydrol., submitted, 2013.

Epting, J., Huggenberger, P., and Rauber, M.: Integrated methods and scenario development for urban groundwater management and protection during tunnel road construction: a case study of urban hydrogeology in the city of Basel, Switzerland, Hydrogeol. J., 16, 575-591, doi:10.1007/s10040-007-0242-5, 2008a.

Epting, J., Huggenberger, P., Regli, C., Spoljaric, N., and Kirchhofer, R.: Integrated Methods for Urban Groundwater Management Considering Subsurface Heterogeneity in: Quantitative Information Fusion for Hydrological Sciences, edited by: Cai, X. and Jim Yeh, T.-C., Studies in Computational Intelligence, Springer Series, 183-218, 2008b.

Epting, J., Huggenberger, P., and Butscher, C.: Thermal groundwater use in urban areas - Spatiotemporal scales and concepts, GQ10 Conference - Groundwater Quality Management in a Rapidly Changing World, 13-18 June 2011, Zürich, 2011.

Ferguson, G.: Characterizing uncertainty in groundwater-source heating and cooling projects in Manitoba, Canada, Energy, 37, 201-206, doi:10.1016/j.energy.2011.11.045, 2012.

Florides, G. and Kalogirou, S.: Ground heat exchangers - A review of systems, models and applications, Renew. Energ., 32, 24612478, doi:10.1016/j.renene.2006.12.014, 2007.

Ferguson, G. and Woodbury, A. D.: Subsurface heat flow in an urban environment, J. Geophys. Res.-Solid, 109, B02402, doi:10.1029/2003JB002715, 2004.

Ferguson, G. and Woodbury, A. D.: Thermal sustainability of groundwater-source cooling in Winnipeg, Manitoba, Can. Geotech. J., 42, 1290-1301, doi:10.1139/T05-057, 2005.

Ferguson, G. and Woodbury, A. D.: Observed thermal pollution and post-development simulations of low-temperature geothermal systems in Winnipeg, Canada, Hydrogeol. J., 14, 12061215, doi:10.1007/s10040-006-0047-y, 2006.

Ferguson, G. and Woodbury, A. D.: Urban heat island in the subsurface, Geophys. Res. Lett., 34, L23713, doi:10.1029/2007g1032324, 2007.

Fry, V. A.: Lessons from London: regulation of open-loop ground source heat pumps in central London, Q. J. Eng. Geol. Hydro., 42, 325-334, doi:10.1144/1470-9236/08-087, 2009.

Fujii, H., Itoi, R., Fujii, J., and Uchida, Y.: Optimizing the design of large-scale ground-coupled heat pump systems using groundwater and heat transport modeling, Geothermics, 34, 347-364, doi:10.1016/j.geothermics.2005.04.001, 2005.

Fujii, H., Inatomi, T., Itoi, R., and Uchida, Y.: Development of suitability maps for ground-coupled heat pump systems using groundwater and heat transport models, Geothermics, 36, 459472, doi:10.1016/j.geothermics.2007.06.002, 2007.

Gandy, C. J., Clarke, L., Banks, D., and Younger, P. L.: Predictive modelling of groundwater abstraction and artificial recharge of cooling water, Q. J. Eng. Geol. Hydro., 43, 279-288, doi:10.1144/1470-9236/08-093, 2010. 
Gringarten, A. C. and Sauty, J. P.: Theoretical-Study of Heat Extraction from Aquifers with Uniform Regional Flow, J. Geophys. Res., 80, 4956-4962, doi:10.1029/Jb080i035p04956, 1975.

GSchV: Gewässerschutzverordnung, The Federal Authorities of the Swiss Confederation, Bern, 2001.

Haehnlein, S., Bayer, P., and Blum, P.: International legal status of the use of shallow geothermal energy, Renew. Sust. Energ. Rev., 14, 2611-2625, doi:10.1016/j.rser.2010.07.069, 2010.

Händel, F., Liedl, R., Fank, J., and Rock, G.: Regional Modeling of Geothermal Energy Systems in Shallow Aquifers: The Leibnitzer Feld Case Study (Austria), Environ. Earth Sci., doi:10.1007/s12665-013-2469-x, in press, 2013.

Häring, M.: Sondierbohrung Otterbach, Basel, Der erste Schritt zur Entwicklung eines geothermischen Heiz-Kraftwerks nach dem Hot-Dry-Rock Verfahren, Bull. Angew. Geol., 7, 19-30, 2002.

Hassanizadeh, S. M.: Modeling Species Transport by Concentrated Brine in Aggregated Porous-Media, Transport Porous Med., 3, 299-318, 1988 .

Huggenberger, P., Epting, J., Kirchhofer, R., Rauber, M., and Miracapillo, C.: Grundwassermanagement Grossraum Basel-West, SGBF - Mitteilung Schweizerische Gesellschaft für Boden und Felsmechanik, Die Nordschweiz und ihre Tiefbauten im Lockergestein, 5 November 2004, Herbsttagung, Muttenz, 2004.

Huggenberger, P., Epting, J., Spottke, I., Regli, C., and Zechner, E.: INTERREG III A-Projekt MoNit "Modellierung der Grundwasserbelastung durch Nitrat im Oberrheingraben" Teilprojekte Nitratherkunft (Nitrat-Transportmodellierung) und FlussGrundwasser-Interaktion (regionale hydrologische Grundlagendaten), Landesanstalt für Umwelt, Messungen und Naturschutz Baden-Württemberg, 2006.

Lever, D. A. and Jackson, C. P.: On the equations of concentrated salt solution through porous medium, UKDOE/RW/85.100, AEA Technology, 1985.

Lopez, S., Hamm, V., Le Brun, M., Schaper, L., Boissier, F., Cotiche, C., and Giuglaris, E.: 40 years of Dogger aquifer management in Ile-de-France, Paris Basin, France, Geothermics, 39, 339-356, doi:10.1016/j.geothermics.2010.09.005, 2010.

Lund, J. W., Freeston, D. H., and Boyd, T. L.: Direct application of geothermal energy: 2005 Worldwide review, Geothermics, 34 , 691-727, doi:10.1016/j.geothermics.2005.09.003, 2005.

Markle, J. M., Schincariol, R. A., Sass, J. H., and Molson, J. W.: Characterizing the two-dimensional thermal conductivity distribution in a sand and gravel aquifer, Soil Sci. Soc. Am. J., 70, 1281-1294, doi:10.2136/sssaj2005.0293, 2006.

Nakayama, T. and Hashimoto, S.: Analysis of the ability of water resources to reduce the urban heat island in the Tokyo megalopolis, Environ. Poll., 159, 2164-2173, doi:10.1016/j.envpol.2010.11.016, 2011.

Nam, Y. and Ooka, R.: Numerical simulation of ground heat and water transfer for groundwater heat pump system based on real-scale experiment, Energ. Build., 42, 69-75, doi:10.1016/j.enbuild.2009.07.012, 2010.
Otto, R.: Zur Bestimmung von Wärmeleitfähigkeiten der oberflächennahen Lockergesteinsschichtenfolge in Norddeutschland, Jahrestagung der DGG in Bochum, RU Bochum, p. 73, 2010.

Pouloupatis, P. D., Florides, G., and Tassou, S.: Measurements of ground temperatures in Cyprus for ground thermal applications, Renew. Energ., 36, 804-814, doi:10.1016/j.renene.2010.07.029, 2011.

Richards, L. A.: Capillary conduction of liquids through porous mediums, Physics - J. Gen. Appl. P., 1, 318-333, doi:10.1063/1.1745010, 1931

Schaap, M. G., Leij, F. J., and van Genuchten, M. T.: ROSETTA: a computer program for estimating soil hydraulic parameters with hierarchical pedotransfer functions, J. Hydrol., 251, 163-176, doi:10.1016/S0022-1694(01)00466-8, 2001.

Shi, B., Liu, C., Wang, B. J., and Zhao, L. Z.: Urban heat Island effect on engineering properties of soil and the related disaster effect, Adv. Earth Sci., 23, 1167-1173, 2008.

Spitler, J. D.: Ground-source heat pump system research - Past, present, and future, Hvac\&R Res., 11, 165-167, 2005.

Taniguchi, M., Shimada, J., Tanaka, T., Kayane, I., Sakura, Y., Shimano, Y., Dapaah-Siakwan, S., and Kawashima, S.: Disturbances of temperature-depth profiles due to surface climate change and subsurface water flow: 1 . An effect of linear increase in surface temperature caused by global warming and urbanization in the Tokyo metropolitan area, Japan, Water Resour. Res., 35, 1507 $1517,1999$.

Taniguchi, M., Uemura, T., and Sakura, Y.: Effects of urbanization and groundwater flow on subsurface temperature in three megacities in Japan, J. Geophys. Eng., 2, 320-325, doi:10.1088/17422132/2/4/S04, 2005.

Taniguchi, M., Ishitobi, T., Burnett, W. C., and Wattayakorn, G.: Evaluating ground water-sea water interactions via resistivity and seepage meters, Ground Water, 45, 729-735, doi:10.1111/j.1745-6584.2007.00343.x, 2007.

Taylor, C. A. and Stefan, H. G.: Shallow groundwater temperature response to climate change and urbanization, J. Hydrol., 375, 601-612, doi:10.1016/j.jhydrol.2009.07.009, 2009.

Vangenuchten, M. T.: A Closed-Form Equation for Predicting the Hydraulic Conductivity of Unsaturated Soils, Soil Sci. Soc. Am. J., 44, 892-898, 1980.

Yamano, M., Goto, S., Miyakoshi, A., Hamamoto, H., Lubis, R. F., Monyrath, V., and Taniguchi, M.: Reconstruction of the thermal environment evolution in urban areas from underground temperature distribution, Sci. Total Environ., 407, 3120-3128, doi:10.1016/j.scitotenv.2008.11.019, 2009.

Zhu, K., Blum, P., Ferguson, G., Balke, K. D., and Bayer, P.: The geothermal potential of urban heat islands, Environ. Res. Lett., 5, 044002, doi:10.1088/1748-9326/5/4/044002, 2010. 